\title{
Multi-objective optimization for optimum tolerance synthesis with process and machine selection using a genetic algorithm
}

\author{
${ }^{\dagger}$ Geetha, K. ${ }^{1}$, Ravindran, D. ${ }^{2}$, Siva Kumar, M. ${ }^{3}$, and Islam, M.N. ${ }^{4}$ \\ ${ }^{1}$ Raja College of Engineering, Madurai, Tamilnadu, India. \\ ${ }^{2}$ National Engineering College, K.R. Nagar, Kovilpatti 628 503, Tamilnadu, India. \\ ${ }^{3}$ Sree Sowdambika College of Engineering, Chettikurichi-626 134, Aruppukottai, Tamilnadu, \\ India. \\ ${ }^{4}$ Curtin University, GPO Box U 1987, Perth, WA 6845, Australia.
}

\begin{abstract}
This paper presents a new approach to the tolerance synthesis of the component parts of assemblies by simultaneously optimizing three manufacturing parameters: manufacturing cost, including tolerance cost and quality loss cost; machining time; and machine overhead/idle time cost. A methodology has been developed using the Genetic Algorithm (GA) technique to solve this multiobjective optimization problem. The effectiveness of the proposed methodology has been demonstrated by solving a wheel mounting assembly problem consisting of five components, two subassemblies, two critical dimensions, two functional tolerances, and eight operations. Significant cost saving can be achieved by employing this methodology.
\end{abstract}

Keywords: Tolerance synthesis, tolerance cost models, optimization techniques, normalization, and manufacturing processes.

\section{Introduction}

Tolerance specification plays an important role in product realization because of its direct relationship with the cost and quality of the product. From a design point of view, tolerance affects the fit and performance of the final product. Conversely, from the manufacturing point of view, tolerance affects the selection of machines, tooling and fixtures, operators' skill levels, setup costs, precision of the inspection instruments, gauging, amount of scrap, and rework. The proper allocation of tolerance among the component parts of a mechanical assembly will reduce the manufacturing cost significantly. Tolerance allocation is the proper distribution of tolerance among the components in mechanical assemblies. Through proper allocation, critical clearance can be maintained and part interchangeability can be assured. Several tolerance allocation methods have been proposed in the literature.

Lee and Woo [1] applied a branch and bound algorithm for handling both the linear and nonlinear assemblies to select the optimum tolerance and process limits. Chase et al. [2] obtained optimum tolerances by applying four different optimization tools, considering both discrete and continuous cost functions, and reported an exhaustive search based on Lagrange's Multiplier (ESLM) approach, which is the most reliable technique to obtain the exact global optima. Zhang and Wang [3] introduced simulated annealing, a nontraditional optimization tool to

\footnotetext{
${ }^{\dagger}$ Corresponding author’s email: gee130372@ymail.com
} 
obtain global optimum advanced tolerance synthesis problems considering the continuous cost function. Sangeet [4] developed an optimization model to allocate tolerances, processes, and machines to the machining operation with the objective of minimizing the manufacturing cost while satisfying technological constraints without overloading the machines. Moiz et al. [5] proposed a new methodology for tolerance allocation and process selection in which the method starts with a solution that minimizes the objective function value, but it is not feasible, and the infeasibility is iteratively reduced with negligible CPU time.

Chang-Xue et al. [6] introduced the design of the experiments' approach for the concurrent selection of component tolerances and the corresponding manufacturing processes with the objective of minimizing the variation of tolerance stack-ups. Ming et al. [7] adopted a Genetic Algorithm (GA) to generate the optimal tolerance for each of the manufacturing operations and utilized a Hopefield neural network to solve the manufacturing operations selection problem. Ye et al. [8] applied a new concurrent engineering method for tolerance allocation. A nonlinear optimization model was constructed to implement the method. The model simultaneously minimized the combination of quality loss and manufacturing cost in a single objective function by setting both process and design tolerances.

Jeang et al. [9] and Singh et al. [10] considered wheel mounting assembly (consisting of two interrelated dimensional chains) for minimizing the total manufacturing cost using an exponential cost function with optimum tolerance allocation. Singh et al. [11] assumed sufficiently wide precision limits for the comparison of the results obtained with the ESLM. Kenneth [12] described several methods for performing tolerance allocation to reduce the overall cost of production while meeting target quality. Diplaris et al. [13] formulated a new analytical cost tolerance model, which produces results closer to industrial practice based on the available industrial knowledge and earlier published data.

Using GA as an optimization tool, Monica et al. [14] developed a methodology to allow the automatic tolerance allocation for minimizing the manufacturing cost. Ji et al. [15] presented a new approach based on the fuzzy comprehensive evaluation and a genetic algorithm to obtain a rational tolerance allocation for the parts. Prabhaharan et al. [16] applied GA for optimal tolerance allocation to help design and manufacturing engineers overcome the shortcomings in the conventional tolerance stack analysis and allocation system. Singh et al. [11] introduced GA to obtain a global optimal solution for the advanced tolerance synthesis problem by considering a continuous cost function. Jain et al. [17] proposed GA to obtain the optimum tolerances of mechanical assemblies with interrelated dimension chains, process precision limits, and alternative process selection.

Chou et al. [18] proposed a model for optimal tolerance allocation by considering both tolerance cost and the present worth of quality loss, so the total assembly cost/loss is minimized. The proposed model considered the time value of money for quality loss and product degradation over time and included two new parameters: the planning horizon and the product user's discount rate. Christopher et al. [19] proposed two efficient algorithms, a Lagrange multiplier and an iterative relative sensitivity analysis, for the optimal allocation of tolerance among the component parts of complex assemblies with a large number of 
constraints and entities. Rao et al. [20] presented an optimum allocation method based on interval analysis to find the optimum values of tolerances and clearances in mechanical assemblies that satisfy both the objective function and functional and design constraints. Gordon et al. [21] invoked probability-constrained optimization to establish a framework for allocating the means and tolerances in the design quality in which the optimal allocation minimized the production costs. Prabhaharan et al. [22] introduced the Continuous Ants Colony Algorithm, a type of meta-heuristic approach, as an optimization tool to minimize the critical dimension deviation and allocate the cost-based optimal tolerances.

Yuan et al. [23] obtained the optimized tolerance allocation of a sliding vane rotary compressor's component parts for the required reliability, the minimum cost, and quality loss. Gopalakrishnan et al. [24] developed a method to minimize the overall quality loss by optimizing the deviations from the nominal dimensions based on Taguchi's loss function. Jean-Yves et al. [25] proposed statistical analysis for tolerance analysis and a genetic algorithm for tolerance synthesis to obtain gear tolerances. Alain et al. [26] proposed an approach to allocate the functional tolerances that provide the best ratio of functional performances to manufacturing cost. The authors used a genetic algorithm for optimization and a constraint satisfaction algorithm for process selection. Fangcai et al. [27] solved nonlinearly constrained tolerance allocation problems to minimize the ratio between the sum of the manufacturing costs (tolerances costs) and the risk (probability of the respect of geometrical requirements) using Monte Carlo simulation and a genetic algorithm. Huanmin et al. [28] presented an atomic inference engine model of process parameter selection in process planning using mathematical logic.

Sivakumar et al. [29, 30] developed a new methodology using an evolutionary algorithm, viz., the Elitist Non-dominated Sorting Genetic Algorithm (NSGA-II), and the Multi-Objective Particle Swarm Optimization (MOPSO) for obtaining an optimal tolerance allocation and alternative process selection for mechanical assembly. Janakiraman and Saravanan [31] developed a method for concurrently minimizing the manufacturing cost of piston and cylinder component parts by optimizing the operating parameters of the machining processes. Sivakumar et al. [32] proposed an optimum tolerance synthesis with process and machine selection for minimizing manufacturing costs and machining time using a genetic algorithm. Rao [33] introduced a concurrent approach for tolerance allocation using evolutionary algorithms with the simultaneous consideration of product design, manufacturing, and quality. Cherng and Tsai [34] presented a systematic method for optimal statistical tolerance allocation using the Lagrange multiplier method for minimizing manufacturing costs subject to constraints on dimensional chains and machining capabilities. Tzu-Chieh and Kuei-Yuan [35] developed a method to perform simultaneous design and tolerance allocation for engineering problems with multiple objectives. Gadallah [36] presented a new formulation for tolerance allocation based on minimum sensitivity using a heuristic approach for optimization.

Jayaprakash et al. [37] introduced an integration of statistical tolerance design method with Finite Element Analysis (FEA) that assured the optimal tolerance values of various component parts of the assembly. Johan and Rikard [38] introduced a top-down tolerance approach where requirements at the 
assembly level on products within a family were allocated to single part requirements. According to Rajesh et al. [39], process planning and scheduling functions strongly influence the profitability of product manufacturing, resource utilization, and product delivery time. The authors developed an integrated process planning and scheduling system applicable to the Holonic Manufacturing System, which accepts dynamic changes in volume and the variety of products. Xinyu et al. [40] developed a genetic-algorithm-based approach to facilitate the integration and optimization of process planning and scheduling. Li et al. [41] introduced three game-theory-based strategies, i.e., the Pareto strategy, the Nash strategy, and the Stackelberg strategy, to systematically analyze the cooperation of computer automated process planning and scheduling. Guo et al. [42] solved the integration of process planning and scheduling problems using a combinatorial optimization model and a modern evolutionary algorithm, i.e., the particle swarm optimization (PSO) algorithm. Hengyun et al. [43] developed a discrete particle swarm algorithm to facilitate integration and optimization based on the objective of minimizing production makespan.

Xinyu et al. [44] developed a hybrid approach, an efficient genetic representation of the operator and local search strategy, to improve the optimization process of integration process planning and scheduling. Xinyu et al. [45] developed a mathematical model of integrated process planning and scheduling and used an evolutionary-algorithm-based approach to facilitate the integration and optimization of IPPS. Kunlei et al. [46] proposed an imperialist competitive algorithm to address the IPPS problem with an objective of makespan minimization. Rakesh et al. [47] discussed three common integration approaches - the non-linear approach, the closed loop approach, and the distributed approach - and their relative advantages and disadvantages. Li et al. [48] developed three strategies, including process flexibility and scheduling flexibility, that have been used for exploring the search space by effective simulates annealing.

Taguchi introduced the concept of the quality loss of a product [49] in which all critical parameters including dimensions of a product should be at their target values to ensure the product's best performance. Huang and Shiau [50] allocated the optimum tolerances of sliding vane rotary compressor components for the required reliability, the minimum cost, and quality loss. Sampathkumar et al. [51] implemented pattern search algorithm to find the optimal tolerance allocation and asymmetric total cost to overcome the shortcomings in the conventional tolerance allocation problem. Huang and Shiau [52] proposed a model that provides an optimal tolerance allocation method for assemblies with the lowest manufacturing cost, the minimum quality loss, and the required reliability index for the normal distribution and lognormal distribution. Muthu et al. [53] employed GA to solve the tolerance allocation problem by considering both the design and manufacturing tolerances so as to minimize the manufacturing cost and quality loss.

From the above literature review, it appears that even though a significant number of attempts have been used in tolerance allocation based on various single or multiple factors, such as tolerance cost, machine idle time cost, and quality loss, no effort has been made in three important manufacturing parameters: manufacturing cost including tolerance cost and quality loss cost, machining time, 
and machine overhead/idle time cost. Hence, in this work, an attempt has been made to optimally allocate the tolerance of component parts of an assembly along with process and machine selection to minimizing manufacturing cost, total machining time, and the overhead/idle cost of machine.

\section{Problem Definition}

In the present scenario, the customer fixes the cost of the product due to globalization and heavy competition in the market. It is mandatory for the manufacturer to reduce the cost of manufacturing. Tolerance plays an important role in determining the manufacturing cost of the product. The function of the product depends on the functional tolerances of critical dimensions. For the operation of a component part, the process and machine selection decide the tolerance, tolerance cost, quality loss cost, machining time, and machine idle cost. Figure 1 represents a schematic model of a product. It is understood from the figure that the operation may perform any possible combination of the process machine. Hence, the problem is treated as a non-polynomial (NP) hard problem.

\section{Mathematical Model}

Tolerance of the component parts greatly influences the manufacturing cost, machining time, machine idle time, and machine overhead cost and depends on the selection of the process machine combination for individual operations. In the present work, the following assumptions have been made to achieve the optimum value:

- The list of operations to be performed to obtain the specific dimension of the component part is known.

- The operation process and the process-machine feasibility matrix are known.

- The tolerance cost function constants, the tolerance machining time constants, and the models are known.

- The subassembly, assembly, and functionality tolerances are known.

- The machine idle time cost and overhead cost are also known.

- The sequence of operations and machines are not considered in this study.

- The quality loss function/cost is included in tolerance allocation.

The objective of the proposed work is the minimization of manufacturing costs and machine idle time costs along with a minimization of total machining time. In any optimization technique, these three objectives should be represented by a single function. However, cost and machining time are not in the same units of measurement. Therefore, normalization is required to bring them into a single unit of measurement. The objective function is repressed by Equation (1), which is the sum of the normalized values of manufacturing cost, machining time, and machine idle time costs. Equations (2) through (4) represent the normalization 
functions for manufacturing cost, machining time, and machine idle time cost, respectively.

$$
\begin{aligned}
& Z=N\left(C_{m f g}\right)+N\left(T_{m t}\right)+N\left(C_{i d}\right) \\
& N\left(C_{m f g, l}\right)=\frac{C_{m f g, l}-\min \left(C_{m f g, l=1,2,3, \ldots n s}\right)}{\max \left(C_{m f g, l=1,2,3, \ldots . n s}\right)-\min \left(C_{m f g, l=1,2,3, \ldots . n s}\right)} \\
& N\left(T_{m t, l}\right)=\frac{T_{m c, l}-\min \left(T_{m c, l=1,2,3, \ldots n s}\right)}{\max \left(T_{m t, l=1,2,3, \ldots n s}\right)-\min \left(T_{m t, l=1,2,3, \ldots n s}\right)} \\
& N\left(C_{i d, l}\right)=\frac{C_{i d, l}-\min \left(C_{i d, l=1,2,3, \ldots n s}\right)}{\max \left(C_{i d, l=1,2,3, \ldots . n s}\right)-\min \left(C_{i d, l=1,2,3, \ldots . n s}\right)}
\end{aligned}
$$

where

$N\left(C_{m f g, l}\right) \quad$ - Normalized value of the manufacturing costs of the $l^{\text {th }}$ sample

$N\left(T_{m t, l}\right) \quad$ - Normalized value of the machining time of the $l^{\text {th }}$ sample

$N\left(C_{i d, l}\right) \quad$ - Normalized value of the machine idle cost of the $l^{\text {th }}$ sample

$l \quad$ - Sample number index

ns $\quad$ - Number of samples

$Z \quad$ - Objective function

$C_{m f g, l} \quad-$ Manufacturing cost of the product for the $l^{\text {th }}$ sample

$T_{m t, l} \quad$ - Machining time of the product for the $l^{\text {th }}$ sample

$C_{i d, l} \quad-$ Machine idle cost for the $l^{\text {th }}$ sample

The following constraints are considered in this work:

- The operation should be performed using any of the possible processes.

- The process should be performed using any of the possible machines.

- The allocated tolerance must be within the process tolerance limits of the selected process, which are given in Equation (5).

- Equation (6) represents the sum of the tolerances of the component parts of a subassembly/assembly that should be less than or equal to the required subassembly/assembly tolerance.

$$
\begin{aligned}
& t_{\text {min }, k} \leq t_{i j k} \leq t_{\max , k} \\
& t_{\text {asm }} \geq \sum_{i=1}^{N} t_{i j k}
\end{aligned}
$$

Equation (7) represents the tolerance cost model as well as the tolerance cost for the $i^{\text {th }}$ operation. The total tolerance cost is determined using equation (8).

$$
C_{m c, i j k}=e f f_{i, j k}\left(a_{i, k}+\frac{b_{i, k}}{t_{i j k}}\right)
$$




$$
C_{m f g}=\sum_{i=1}^{N} C_{m c, i j k}+C_{Q L}
$$

where

$$
C_{Q L}=\frac{A}{\Delta^{2}}(y-m)^{2}
$$

$C_{Q L} \quad$ - Quadratic quality loss cost

$A$ - Cost of repairing of the product

$\Delta \quad$ - Required specification of the product

$y \quad$ - Target value

$m \quad-$ Deviation from the target value

$i \quad$ - Operation number index

$j \quad$ - Machine number index

$k \quad$ - Process number index

$N \quad$ - Number of operations

$P \quad$ - Number of processes

$M \quad$ - Number of machines

$t_{m i n, k} \quad-$ Minimum process tolerance in the $k^{\text {th }}$ process

$t_{\text {max }, k} \quad-$ Maximum process tolerance in the $k^{\text {th }}$ process

$t_{i j k} \quad-i^{\text {th }}$ operation tolerance using the $k^{\text {th }}$ process on the $j^{\text {th }}$ machine

$t_{a s m} \quad-$ Assembly tolerance

$a_{i, k}$ and $b_{i, k} \quad$ - Tolerance cost model constants of the $k^{\text {th }}$ process of the $i^{\text {th }}$ operation

eff $f_{i, j k} \quad-$ Efficiency factor of the $i^{\text {th }}$ operation for the $k^{\text {th }}$ process on the $j^{\text {th }}$ machine

$C_{m c, i j k} \quad-$ Tolerance cost of the $i^{\text {th }}$ operation for the $k^{\text {th }}$ process on the $j^{\text {th }}$ machine

The model of machining time calculation as well as the $i^{\text {th }}$ operation machining time can be determined using Equation (9). The total machining time of the product is estimated using Equation (10). The machine engaged time, idle time, and idle time costs are determined using Equations (11), (12), and (13), respectively. The machine idle time is calculated based on the difference between the maximum machine engaged time and the individual machine engaged time.

$$
\begin{aligned}
& T_{m t, i j k}=e f f_{i, j k}\left(X_{i, k}+\frac{Y_{i, k}}{t_{i j k}}\right) \\
& T_{m t}=\sum_{i=1}^{N} T_{m c, i j k} \\
& T_{m e, j}=T_{m t, i j k} \\
& T_{i d, j}=\max \left|T_{m e, j=1,2,3, \ldots . M}\right|-T_{m e, j}
\end{aligned}
$$




$$
C_{i d}=\sum_{j=1}^{M} C_{o, j} T_{i d, j}
$$

where

\begin{tabular}{|c|c|}
\hline$T_{m t, i j k}$ & $\begin{array}{l}\text {-Machining time for the } i^{\text {th }} \text { operation on the } j^{\text {th }} \text { machine for the } k^{\text {th }} \\
\text { process }\end{array}$ \\
\hline$X_{i, k}$ and $Y_{i, k}$ & $\begin{array}{l}\text {-Tolerance time model constants of the } k^{\text {th }} \text { process of the } i^{\text {th }} \\
\text { operation }\end{array}$ \\
\hline$T_{m t}$ & -Total machining time for the product \\
\hline$T_{m e, j}$ & $-j^{\text {th }}$ machine engaged time in min \\
\hline$T_{i d, j}$ & -Idle time of the $j^{\text {th }}$ machine \\
\hline$C_{o, j}$ & $-j^{\text {th }}$ machine idle time cost per min \\
\hline$C_{i d}$ & -Total idle time cost during the completion of the product \\
\hline
\end{tabular}

\section{Methodology}

Tolerance allocation is a difficult task, as mathematically there are an infinite number of combinations of individual tolerance values that satisfy each objective function; however, some solutions are better than others. The purpose of a tolerance allocation strategy is to find the best possible combination of individual tolerances. In this case, the difficulty is exacerbated by the fact that we are trying to concurrently accomplish several objectives: minimizing tolerance cost and quality loss cost, machining time, and machine idle time cost. This problem behaves similarly to an NP hard optimization problem. A Genetic Algorithm (GA), which is used to solve the characteristics of discrete search methods and probabilities selection, was proposed to solve the problem based on the mechanisms of natural genetics and natural selection to arrive at a highly reliable global optimal solution. A general view of GA is illustrated in Figure 2.

\section{Numerical Illustration}

The proposed methodology has been demonstrated on a wheel mounted assembly, which is shown in Figure 3. Earlier, the same problem was dealt with by Singh et al. by considering alternative processes and alternative machines. However, the machining time was not considered; the objective function was to minimize the manufacturing cost only. In this work, the same five components are considered with the assumption of eight operations (sub-stages) required to complete the job whereas Singh et al. considered five operations only (no sub-stages were required to manufacture the components). The details are presented in Table 1. The proposed method enhances the existing method by considering machining time to complete the operation. The assignment of machine and process plays a vital role in reducing the machining time of the component. It consists of five component parts, and eight operations are required to complete the job (details are presented in Table 1). The required functional tolerance for the critical dimensions $Y 1$ and $Y 2$ are $0.21 \mathrm{~mm}$ and $0.42 \mathrm{~mm}$, respectively. The value of $A$ for the critical dimensions $Y 1$ and $Y 2$ are assumed as $\$ 100$ and $\$ 200$, respectively. The possible processes for individual operations and the possible machines for individual 
process are listed in Table 2. A flowchart representing the present work is shown in Figure 4. The tolerance-manufacturing cost and the process tolerancemachining time relationships are given in Figures 5 and 6, respectively. The cost and time function constants are listed in Table 3. The idle time cost of M1, M2, $\mathrm{M} 3$, and M4 are assumed to be $\$ 5.4, \$ 4.6, \$ 7.8$, and $\$ 10.2$, respectively.

The values of critical dimensions $Y 1$ and $Y 2$ and their tolerances can be determined using Equations (14) through (17). Equations (14) and (15) are the simple dimensional chains that show the calculations of the values of critical dimensions $Y 1$ and $Y 2$. The tolerances have cumulative effects, which are represented by Equations (16) and (17). Two different cases in subassembly tolerances have been introduced for the example problem, given in Table 4.

$$
\begin{aligned}
& Y 1=X 2-X 4 \\
& Y 2=X 5-X 1-X 2-X 3 \\
& t_{Y 1}=t_{X 2}+t_{X 4} \\
& t_{Y 2}=t_{X 5}+t_{X 1}+t_{X 2}+t_{X 3}
\end{aligned}
$$

where

$$
\begin{array}{ll}
t_{X_{1}}=t_{o_{1}}+t_{o 2} & \\
t_{X_{21}}=t_{o_{7}}+t_{o 8} & \\
t_{X_{31}}=t_{o 4}+t_{o 5} & \\
t_{X 4}=t_{o 3} & \\
t_{X 5}=t_{o 6} & \\
t_{o 1}=t_{o 8} \quad \text {-Tolerance obtained from operations } 1 \text { through } 8
\end{array}
$$

The GA representation of the problem and the GA parameter values are given in Tables 5 and 6 , respectively. The chromosome has a set of two numbers, discrete and binary, for individual operations. The discrete number represents a random number generated within the maximum possible process machine combination of individual operations. The binary number represents the allocated tolerance value for an individual operation. Equations (18) and (19) are used to calculate the decimal equivalents for individual processes and the allocated tolerance for an individual operation. For demonstration purposes, six chromosomes are considered the initial population, shown in Table 7.

$$
\begin{aligned}
& D_{e, k}=\frac{t_{\max , k}-t_{\min , k}}{2^{n b}-1} \\
& t_{i j k}=D_{e, k} B t D\left(B N_{i}\right)+t_{\min , k}
\end{aligned}
$$

where
$D_{e, k}$
$B N_{i}$
- Decimal equivalent of the $k^{\text {th }}$ process
$B t D()$
$-i^{\text {th }}$ operation binary number
$n b$
- Function to convert the binary to a decimal
- Number of bits 


\section{Results and Discussion}

The details of the objective function combinations considered in this present work are listed in Table 8 . A number of trials have been carried out for the two different cases outlined in Table 4 for different numbers, from 7 bits to 21 bits, for all the objective functions mentioned in Table 8. For demonstration purposes, Table 9 shows the outcome of the objective function of minimizing the manufacturing cost for different bit numbers (7-21). For case 1, the best results are obtained in the bit numbers between 11 and 14. Without considering the quality loss cost, the optimum allocated tolerance for each operation, the subassembly tolerances, the machining time for each operation, the minimum manufacturing cost, the total machining time, and the machine overhead/idle time cost are presented in Tables 10 and 11 for cases 1 and 2, respectively. Similar to case 1 , in case 2 , the best results are obtained between 11 and 14 bit numbers. Tables 12 and 13 represent the best results of case 1 and case 2 with considering quality loss.

Figure 7 illustrates the quadratic quality loss cost for both case 1 and case 2 for different objective function combinations. It is observed that the quality loss cost of case 2 is almost minimum as compared with case 1 , since in case 2 only smaller variations are allowed in the subassembly tolerance values (tolerance on critical dimension).

Figures 8 and 9 represent the results for cases 1 and 2 for different objective combinations with and without considering the quality loss cost. From the above figures, it is clear that there is considerable difference between maximum and minimum values of manufacturing cost; machining time and machine idle time cost are less in without considering quality loss cost as compared with considering quality loss cost. This shows the importance of considering the quality loss cost in tolerance allocation. It is also understood that the objective functions are minimal, while considering all objective functions together. If any one objective is neglected, then the results yield an increase in the cost of the product. Hence, it is proven in this paper that it is necessary to consider the entire objective function. This also holds for case 2 . The best objective values for case 1 are $\$ 39.43$ (manufacturing cost), $72.38 \mathrm{~min}$ (total machining time), and $\$ 42.88$ (overhead cost/idle time cost). Similarly, for case 2, the objective values are \$35.45 (manufacturing cost), $77.92 \mathrm{~min}$ (total machining time), and \$168.1 (overhead cost/idle time cost).

\section{Concluding Remarks}

The optimum tolerance allocation for machine and process selection is cumbersome when the product consists of more subassemblies, component parts, and operations. In this work, GA has been implemented to solve the above NP hard problem. The proposed method has been demonstrated with the example product of a wheel mounting assembly. Optimized tolerance values for each operation of the example product are obtained through process and machine selection using GA, in which the manufacturing cost (including tolerance cost and quality loss cost), the total machining time, and the machine idle time cost are 
considered to be objective functions. Two different cases have been considered in subassembly tolerances. In both cases, it is shown that the consideration of individual objective values would yield an incorrect selection of machine and process rather than considering the three objectives concurrently.

The proposed approach can be applied to statistical tolerance allocation problems in a large number of operations and process machine combinations. Significant cost saving can be achieved by employing the proposed methodology. Ample opportunities are available to widen the scope of the problem by adding more constraints, such as available machine time, cost of machines, machines bottlenecks, etc., and modifying the objective functions, like minimizing initial investments in machines, minimizing the total idle time of machines, minimizing the number of machines used to perform the operations, and a combination of these objectives. These calculations can be introduced in multi-objectives and converted into a single objective. Future research work that considers the sequence of operations and machines can be carried out. The present approach is equally applicable to two- and three-dimensional problems.

\section{References}

1. Lee W J , Woo T C(1989), Optimum selection of discrete tolerances, $\mathrm{T}$. ASME. J. Mech. Transmissions. Autom. Des., 111: 243-251.

2. Chase K W, Greenwood W.H, Loosli B.G, Hauglund L.F(1990), Least Cost tolerance allocation for mechanical assemblies with automated process selection, Manuf. Rev., 3(1): 49-59.

3. Zhang C , Wang H P(1993), The discrete tolerance optimization problem, Manuf. Rev., 6(1):60-71.

4. Sangeet Uttam (2001), Optimal tolerance synthesis for process selection with machine selection. M.S.Thesis, University of Cincinnati.

5. Moiz Y Nagarwala, Simin Pulat P, Shivakumar Raman (1995), A Slope-Based Method for Least Cost Tolerance Allocation, Concurrent Engineering, 3(4):319-328.

6. Chang-Xue (Jack) Feng, Andrew Kusiak (2000), Robust Tolerance Synthesis with the Design of Experiments Approach, Journal of Manufacturing Science and Engineering, 122(3): 520-528.

7. Ming X G, Mak K L (2001), Intelligent Approaches to Tolerance Allocation and Manufacturing Operations Selection in Process Planning, Journal of Materials Processing Technology,117(1-2):75-83.

8. Ye B , Salustri F A (2003), Simultaneous Tolerance Synthesis for Manufacturing and Quality, Research in Engineering Design,14 (2):98-106.

9. Jeang A ,Chang C L (2002),Combined Robust Parameter and Tolerance Design using Orthogonal Arrays, International Journal of Advanced Manufacturing Technology, 19(6): 442-447.

10. Singh P K , Jain P K , Jain S C (2004a), A Genetic Algorithm based Solution to Optimal Tolerance Synthesis of Mechanical Assemblies with Alternative Manufacturing Processes: Focus on Complex Tolerancing Problems, International Journal of Production Research , 42(24):5185-5215.

11. Singh P K , Jain S C , Jain P K (2004b), A Genetic Algorithm based Solution to Optimum Tolerance Synthesis of Mechanical Assemblies with Alternate 
Manufacturing Processes - Benchmarking with the Exhaustive Search Method Using the Lagrange Multiplier, Proc. IMechE, Part B Journal of Engineering Manufacture, 218(B7):765-778.

12. Kenneth W Chase (1999a), 'Minimum Cost Tolerance Allocation', ADCATS Report No. 99-5, Department of Mech. Engg., Brigham Young University.

13. Dilplaris S C, Sfantsikopoulos P (2001), Cost - tolerance function: A new approach for cost optimum machining accuracy, International Journal of Advanced Manufacturing Technology, 16(1): 32-38.

14. Monica Carfagni, Lapo Governi , Francesco Fhiesi (2001), Development of a method for automatic tolerance allocation, Proceeding of the XII ADM International Conference, Italy, D1-20 - D1-27.

15. Ji S, Li X , Ma Y,Cai H (2000), Optimal Tolerance Allocation based on Fuzzy Comprehensive Evaluation and Genetic Algorithm, International Journal of Advanced Manufacturing Technology, 16(7):461-468.

16. Prabhaharan G, Asokan P, Ramesh P, Rajendran S (2004), Genetic-Algorithm - based Optimal Tolerance Allocation using a Least - Cost Model,International Journal of Advanced Manufacturing Technology,24(910):647-660.

17. Singh P K , Satish C Jain, Pramod K Jain (2005), Advanced Optimal Tolerance Design of Mechanical Assemblies with Interrelated Dimension Chains and Process Precision Limits, Computers in Industry, 56(2):179-194.

18. Chou C Y , Chang C L (2001), Minimum-Loss Assembly Tolerance Allocation by Considering Product Degradation and Time Value of Money, International Journal of Advanced Manufacturing Technology, 17(2):139-146.

19. Christopher C Yang , Achuthanaikan V N (2003), Optimum Tolerance Design for Complex Assemblies using Hierarchical Interval Constraint Networks, Computers and Industrial Engineering, 45(3): 511-543.

20. Rao S, Wu W (2005), Optimum Tolerance Allocation in Mechanical Assemblies using an Interval Method, Engineering Optimization, 37(3):237257.

21. Gordon J. Savage, Dehui Tong and Stephen M. Carr (2005), Optimal Mean and Tolerance Allocation Using Conformance-based Design, Quality and Reliability Engineering International, 22(4):445- 472.

22. Prabhaharan G, Asokan P, Rajendran S (2005), Sensitivity-based Conceptual Design and Tolerance Allocation using the Continuous Ants Colony Algorithm (CACO), International Journal of Advanced Manufacturing Technology, 25(5-6): 516-526.

23. Yuan Mao Huang ,Ching-Shin Shiau (2006), Optimal Tolerance Allocation for a Sliding Vane Compressor, Journal of Mechanical Design, 128(1):98-107.

24. Jean-Yves Dantan, Je'rome Bruyere, Jean-Paul Vincent and Regis Bigot (2009), Vectorial tolerance allocation of bevel gear by discrete optimization, Mechanism and Machine Theory, 43: 1478-1494.

25. GopalaKrishnan B, Jaraiedi M ,Iskander W H, Ahmad A(2007), Tolerance Synthesisbased on Taguchi Philosopy, International Journal of Industrial and Systems Engineering, 2(3):331 - 326.

26. Alain Etienne, Jean-Yves Dantan, Jawad Qureshi, Ali Siadat (2008), Variation Management by functional tolerance allocation and manufacturing process 
selection, International Journal on Interactive Design and Manufacturing, 2(4): 207-218.

27. Fangcai Wua, Jean-Yves Dantan, Alain Etienne, Ali Siadat, Patrick Martin (2009), Improved algorithm for tolerance allocation based on Monte Carlo simulation and discrete optimization, Computers \& Industrial Engineering, 56:1402-1413.

28. Huanmin Xu Ã, Dongbo Li (2009), Modeling of process parameter selection with mathematical logic for process planning, Robotics and ComputerIntegrated Manufacturing, 25(3): 529-535.

29. Sivakumar K , Balamurugan C, Ramabalan S, Venkata Raman S B (2009), Optimal concurrent dimensional and geometrical tolerancing based on evolutionary algorithms, World Congress on Nature \& Biologically Inspired Computing (NaBIC 2009), 300 - 305.

30. Sivakumar K, Balamurugan C, Ramabalan S(2010), Concurrent multiobjective tolerance allocation of mechanical assemblies considering alternative manufacturing process selection, The International Journal of Advanced Manufacturing Technology, 53(5-8):711-732.

31. Janakiraman V, Saravanan R (2010), Concurrent optimization of machining process parameters and tolerance allocation, The International Journal of Advanced Manufacturing Technology, 51(1-4):357-369.

32. Sivasubramanian R, Siva Kumar M (2010), Optimum Tolerance Synthesis with Process and Machine Selection for Minimizing Manufacturing Cost and Machining Time by Using Genetic Algorithm, Journal of Manufacturing Technology Research, 2(1-2):93-108.

33. Rao Y S (2011), Simultaneous Tolerance Synthesis for Manufacturing and Quality using Evolutonary Algorithms, International Journal of Applied Evolutionary Computation (IJAEC), 2(2):1-20.

34. Kuo Ming Cheng, Jhy Cherng Tsai (2011), Optimal Statistical Tolerance Allocation of Assemblies for Minimum Manufacturing Cost, Applied Mechanics and Materials, 52-54, 1818-1823.

35. Mohamed H Gadallah (2011), Least sensitive tolerance allocation, International Journal of Quality Engineering and Technology, 2(4):344 - 356.

36. Tzu-Chieh Hung , Kuei-Yuan Chan (2012), Multi-objective design and tolerance allocation for single and multi-level systems, Journal of Intelligent Manufacturing, DOI 10.1007/s10845-011-0608-3.

37. Jayaprakash G, Sivakumar K , Thilak M (2012), FEA compliant parametric tolerance allocation of mechanical assembly using neural network and differential evolution algorithm, International Journal of Computer Integrated Manufacturing, DOI:10.1080/0951192X.2012.665184.

38. Lööf, Johan ; Söderberg, Rikard, (2012), Discrete tolerance allocation for product families, Engineering Optimization, 44(1):75-85.

39. Rajesh S , Toshihiro T , Koji I, Nobuhiro S (2008), A study on integration of process planning and scheduling system for holonic manufacturing with modification of process plans, International Journal of Manufacturing Technology and Management, 14(3/4):359 - 378.

40. Xinyu Li, Liang Gao, Xinyu Shao, Chaoyong Zhang, Cuiyu Wang (2010), Mathematical modeling and evolutionary algorithm-based approach for 
integrated process planning and scheduling, Computers \& Operations Research, 37(4): 656-667.

41. Li W D, Gao L, Li X Y, Guo Y (2008), Game Theory-Based Cooperation of Process Planning and Scheduling. In: Proceeding of CSCWD, pp 841-845. IEEE Press, New York.

42. Guo Y W, Li W D, Mileham A R, Owen G W(2009), Applications of particle swarm and optimization in integrated process planning and scheduling. Robotics and Computer-Integrated Manufacturing, 25: 280-288.

43. Hengyun Z, Wenhua Y,Guangxia B(2009), A particle swarm optimization for integrated process planning and scheduling, International Conference on Computer-Aided Industrial Design \& Conceptual Design, CAID \& CD 2009. $1070-1074$

44. Xinyu Li, Liang Gao, Guohui Zhang, Chaoyong Zhang, Xinyu Shao (2008), A Genetic Algorithm for Integration of Process Planning and Scheduling Problem, C. Xiong et al. (Eds.): ICIRA 2008, Part II, LNAI 5315, pp 495502.

45. Xinyu Li, Xinyu Shao, Liang Gao, Weirong Qian (2010), An effective hybrid algorithm for integrated process planning and scheduling, International Journal of Production Economics, 126(2): 289-298.

46. Kunlei Liana, Chaoyong Zhanga, Liang Gaoa and Xinyu Lia (2011), Integrated process planning and scheduling using an imperialist competitive algorithm, International Journal of Production Research, DOI:10.1080/00207543.2011.622310.

47. Rakesh K , Phandena, Ajai J , Rajiv V (2011), Integration of process planning and scheduling: a state-of-the-art review, International Journal of Computer Integrated Manufacturing, 24(6):517-534.

48. Li W D, McMahon C A (2007), A Simulated Annealing - Based Optimization Approach for Integrated Process Planning and Scheduling. International. Journal of. Computer Integrated Manufacturing, 20(1): 80-95.

49. Taguchi G., Elsayed E A and Hsiang T C (1989) Quality engineering in production systems, McGraw-Hill book Co., New York.

50. Yuan Mao Huang and Ching-Shin Shiau (2006), Optimal tolerance allocation for a sliding vane compressor, Journal of Mechanical Design - Transactions of the ASME, 128:98-107.

51. Sampath kumar R., Alagumurthi N and Ramesh R (2009), Optimization of design tolerance and asymmetric quality loss cost using pattern search algorithm, International Journal of Physical Sciences, 4 (11):629-637.

52. Yuan Mao Huang, Ching-Shin Shiau, (2009), An optimal tolerance allocation model for assemblies with consideration of manufacturing cost, quality loss and reliability index, Assembly Automation, 29(3):220-229.

53. Muthu P., Dhanalakshmi V and Sankaranarayanasamy K (2010), Design and manufacturing tolerances optimization with quality loss functions, International Journal of Advanced Operations Management, 2(1/2):90-107 


\section{List of Tables}

Table 1: Component Details of Wheel Mounting Assembly

Table 2: Operation - Process and Process - Machine Feasibility Matrix

Table 3: Cost and Time Function Constants

Table 4: Case details of example problem

Table 5: GA Representation of the Problem

Table 6: GA Parameter's Value

Table 7: Initial Population

Table 8: Details of objective function combination

Table 9: Case 1 - Minimum manufacturing cost for different bit numbers

Table 10: Best results of case 1 without quality loss cost

Table 11: Best results of case 2 without quality loss cost

Table 12: Best results of case 1 with quality loss cost

Table 13: Best results of case 2 with quality loss cost

\section{List of Figures}

Figure 1: General Product Structure

Figure 2: General View of Genetic Algorithm

Figure 3. Wheel Mounting Assembly

Figure 4: Scheme of the present work

Figure 5: Tolerance Cost Curves

Figure 6: Tolerance Time Curves

Figure 7: Quadratic quality loss cost for case 1 and case 2 for different objective combinations

Figure 8: Comparison of case 1 with and without quality loss cost

Figure 9: Comparison of case 2 with and without quality loss cost 
Table 1: Component Details of Wheel Mounting Assembly

\begin{tabular}{lll}
\hline Name of the component & Dimension & List of operations \\
\hline Leftside Support & X1 & O1 \& O2 \\
Wheel & X4 & O3 \\
Rightside Support & X3 & O4 \& O5 \\
Shaft & X5 & O6 \\
Spacer & X2 & O7 \& O8 \\
\hline
\end{tabular}

Table 2: Operation - Process and Process - Machine Feasibility Matrix

\begin{tabular}{|c|c|c|c|c|c|c|c|c|c|c|c|c|}
\hline \multirow{2}{*}{$\begin{array}{l}\text { Process } \\
\text { numbers }\end{array}$} & \multicolumn{8}{|c|}{ Operation numbers } & \multicolumn{4}{|c|}{ Machine Numbers } \\
\hline & $\mathrm{O} 1$ & $\mathrm{O} 2$ & $\mathrm{O} 3$ & $\mathrm{O} 4$ & O5 & O6 & $\mathrm{O} 7$ & O8 & M1 & M2 & M3 & M4 \\
\hline $\mathrm{P} 1$ & 1 & 1 & 0 & 0 & 1 & 0 & 0 & 1 & 1 & 0 & 1 & 0 \\
\hline $\mathrm{P} 2$ & 1 & 0 & 1 & 0 & 0 & 1 & 0 & 1 & 0 & 1 & 1 & 0 \\
\hline P3 & 0 & 1 & 0 & 1 & 0 & 0 & 1 & 0 & 1 & 0 & 1 & 1 \\
\hline $\mathrm{P} 4$ & 1 & 0 & 1 & 0 & 1 & 0 & 1 & 0 & 0 & 1 & 1 & 0 \\
\hline P5 & 0 & 1 & 0 & 1 & 0 & 1 & 0 & 0 & 1 & 1 & 0 & 1 \\
\hline
\end{tabular}


Table 3: Cost and Time Function Constants

\begin{tabular}{ccccccccccc}
\hline & \multicolumn{2}{c}{$\begin{array}{c}\text { Cost } \\
\text { function } \\
\text { constant }\end{array}$} & \multicolumn{2}{c}{$\begin{array}{c}\text { Time } \\
\text { function } \\
\text { constant }\end{array}$} & \multicolumn{2}{c}{$\begin{array}{c}\text { Process } \\
\text { capability } \\
\text { limits in mm }\end{array}$} & \multicolumn{4}{c}{$\begin{array}{c}\text { Cost and Time } \\
\text { manipulating Factor } \\
\text { Machine Numbers }\end{array}$} \\
\cline { 2 - 12 } & $\mathrm{a}$ & $\mathrm{b}$ & $\mathrm{X}$ & $\mathrm{Y}$ & $\mathrm{t}_{\min }$ & $\mathrm{t}_{\max }$ & $\mathrm{M} 1$ & $\mathrm{M} 2$ & $\mathrm{M} 3$ & $\mathrm{M} 4$ \\
\hline P1 & 1.4 & 0.24 & 2 & 0.4 & 0.01 & 0.08 & 0.8 & 0 & 1.15 & 0 \\
P2 & 1.5 & 0.22 & 5 & 0.2 & 0.03 & 0.09 & 0 & 0.85 & 1 & 0 \\
P3 & 0.9 & 0.18 & 3 & 0.8 & 0.02 & 0.07 & 0.85 & 0 & 0.9 & 1.02 \\
P4 & 2.5 & 0.23 & 4.5 & 0.5 & 0.03 & 0.13 & 0 & 1.11 & 0.95 & 0 \\
P5 & 1.9 & 0.15 & 3 & 0.2 & 0.009 & 0.1 & 1.08 & 1.01 & 0 & 0.8 \\
\hline
\end{tabular}

Table 4: Case details of example problem

\begin{tabular}{lll}
\hline Case & Subassembly 1 & Subassembly 2 \\
\hline Case 1 & $\mathrm{t}_{\mathrm{Y} 1} \leq 0.21$ & $\mathrm{t}_{\mathrm{Y} 2} \leq 0.42$ \\
Case 2 & $0.20 \leq \mathrm{t}_{\mathrm{Y} 1} \leq 0.21$ & $0.41 \leq \mathrm{t}_{\mathrm{Y} 1} \leq 0.42$
\end{tabular}

Table 5: GA Representation of the Problem

\begin{tabular}{|c|c|c|c|c|c|c|c|c|c|c|c|c|c|c|c|}
\hline \multicolumn{16}{|c|}{ Representation of Gene } \\
\hline \multicolumn{9}{|c|}{$\begin{array}{l}\text { Discrete Number represents process machine } \\
\text { Combination (DN) }\end{array}$} & \multicolumn{7}{|c|}{$\begin{array}{l}\text { Binary Number represents tolerance } \\
\text { (BN) }\end{array}$} \\
\hline \multicolumn{9}{|c|}{3} & \multicolumn{7}{|c|}{10010110} \\
\hline \multicolumn{16}{|c|}{ Representation of chromosome } \\
\hline 4 & 1011010 & 4 & 100100 & 1 & 11001101 & 4 & 100100 & 1 & 1101 & 1 & 11001101 & 4 & 100100 & 1 & 11001101 \\
\hline
\end{tabular}


Table 6: GA Parameter's Value

\begin{tabular}{|ll|}
\hline \multicolumn{1}{|c|}{ Particulars } & Value / Method \\
Population Size & 40 \\
SelectionProcess method & Roulette wheel selection \\
Cross over probability & 0.5 \\
Cross over method & Single point \\
Mutation probability & 0.03 \\
Replacement strategy & Complete replacement \\
Stopping criteria & 1000 iterations or no change in 50 consecutive iteration fitness value \\
\hline
\end{tabular}

Table 7: Initial Population

\begin{tabular}{rrlrlrlrl}
\hline & \multicolumn{2}{l}{ O1 } & \multicolumn{2}{l}{ O2 } & \multicolumn{2}{l}{ O3 } & \multicolumn{2}{c}{ O4 } \\
\cline { 2 - 9 } C.No. & DN & BN & DN & BN & DN & BN & DN & BN \\
\hline 1 & 4 & 01011010 & 6 & 11001011 & 1 & 10110001 & 4 & 00010100 \\
2 & 3 & 01110101 & 1 & 11110101 & 1 & 11101010 & 6 & 10010001 \\
3 & 3 & 11001010 & 4 & 01010001 & 3 & 10100100 & 5 & 00110001 \\
4 & 4 & 11100111 & 7 & 11111111 & 2 & 11100111 & 3 & 10100001 \\
5 & 5 & 11110000 & 2 & 01000010 & 1 & 10010011 & 6 & 10110111 \\
6 & 2 & 01101011 & 2 & 01110011 & 2 & 00001001 & 1 & 10100111 \\
\hline & & & & & & & & \\
\hline & & $\mathbf{O 5}$ & & $\mathbf{O 6}$ & & $\mathbf{O 7}$ & & O8 \\
\hline 1 & 4 & 00100100 & 1 & 11001101 & 4 & 00100100 & 1 & 11001101 \\
2 & 1 & 10101000 & 2 & 00110101 & 1 & 10101000 & 2 & 00110101 \\
3 & 2 & 10101010 & 4 & 00001111 & 2 & 10101010 & 4 & 00001111 \\
4 & 2 & 10110000 & 1 & 11111010 & 2 & 10110000 & 1 & 11111010 \\
5 & 3 & 01001010 & 3 & 11001101 & 3 & 01001010 & 3 & 11001101 \\
6 & 3 & 00001111 & 1 & 11011111 & 3 & 00001111 & 1 & 11011111 \\
\hline
\end{tabular}


Table 8: Details of objective function combination

\begin{tabular}{lll}
\hline Ob.No. & $\begin{array}{l}\text { Objective } \\
\text { function }\end{array}$ & Details \\
\hline 1 & $\mathrm{Z} 1$ & $\begin{array}{l}\text { Minimizing total manufacturing cost } \\
\text { Minimizing total machining time }\end{array}$ \\
3 & $\mathrm{Z} 2$ & Minimizing machine overhead/idle time cost \\
4 & $\mathrm{Z} 3$ & $\begin{array}{l}\text { Both minimizing total manufacturing cost and minimizing } \\
\text { total machining time } \\
\text { Both minimizing total manufacturing cost and minimizing } \\
\text { machine overhead/idle time cost } \\
\text { Both minimizing total machining time and minimizing } \\
\text { machine overhead/idle time cost } \\
\text { Both minimizing total manufacturing cost, minimizing total } \\
\text { machining time and minimizing machine overhead/idle time } \\
\text { cost }\end{array}$ \\
\hline
\end{tabular}

Ob.No. - Objective Number

Table 9: Case 1 - Minimum manufacturing cost for different bit numbers without quality loss cost

\begin{tabular}{|c|c|c|c|c|c|c|c|c|c|c|c|c|}
\hline $\begin{array}{l}\text { No } \\
\text { of } \\
\text { bits }\end{array}$ & Y1 & Y2 & $\mathrm{C}_{\mathrm{mfg}}$ & $\begin{array}{l}\mathrm{N}(\mathrm{C} \\
\mathrm{mfg})\end{array}$ & $T_{m c}$ & $\mathbf{N}\left(\mathbf{T}_{\mathrm{mc}}\right)$ & $\mathrm{C}_{\mathrm{id}}$ & $\mathbf{N}\left(C_{i d}\right)$ & $\begin{array}{c}\text { N( } \\
\mathbf{Z 1} \\
+ \\
\mathbf{Z 2}) \\
\end{array}$ & $\begin{array}{l}\text { N( } \\
\text { Z1+ } \\
\text { Z3) }\end{array}$ & $\begin{array}{l}\mathrm{N}( \\
\mathrm{Z2}+ \\
\mathrm{Z3})\end{array}$ & $\begin{array}{l}\mathbf{N}(\mathrm{Z1} 1 \\
+\mathrm{Z2} \\
+\mathrm{Z3}) \\
\end{array}$ \\
\hline 7 & 0.1786 & 0.4013 & 49.1 & 0.97 & 92.92 & 0.63 & 289.2 & 0.17 & 1.6 & 1.14 & 0.8 & 1.77 \\
\hline 8 & 0.1826 & 0.3695 & 43.3 & 0.41 & 84.77 & 0.3 & 280.6 & 0.16 & 0.71 & 0.57 & 0.46 & 0.87 \\
\hline 9 & 0.1708 & 0.4153 & 45.3 & 0.61 & 92.59 & 0.62 & 611.2 & 0.53 & 1.23 & 1.14 & 1.15 & 1.76 \\
\hline 10 & 0.182 & 0.4083 & 41.7 & 0.26 & 78.73 & 0.05 & 401 & 0.29 & 0.32 & 0.56 & 0.35 & 0.61 \\
\hline 11 & 0.1778 & 0.4189 & 39 & 0 & 77.43 & 0 & 204.3 & 0.07 & 0 & 0.07 & 0.07 & 0.07 \\
\hline 12 & 0.199 & 0.3497 & 46.9 & 0.76 & 88.29 & 0.44 & 901.5 & 0.86 & 1.21 & 1.62 & 1.3 & 2.06 \\
\hline 13 & 0.1574 & 0.351 & 47.7 & 0.84 & 88.97 & 0.47 & 140.2 & 0 & 1.31 & 0.84 & 0.47 & 1.31 \\
\hline 14 & 0.1696 & 0.4098 & 39.9 & 0.09 & $\begin{array}{l}80.77 \\
101.8\end{array}$ & 0.14 & 261.9 & 0.14 & 0.22 & 0.22 & 0.27 & 0.36 \\
\hline 15 & 0.1595 & 0.3551 & 49.4 & 1 & 4 & 1 & 689 & 0.62 & 2 & 1.62 & 1.62 & 2.62 \\
\hline 16 & 0.1453 & 0.3822 & 45.3 & 0.61 & 91.37 & 0.57 & 697.3 & 0.63 & 1.18 & 1.24 & 1.2 & 1.81 \\
\hline 17 & 0.139 & 0.4085 & 43.1 & 0.39 & 97.01 & 0.8 & 591.4 & 0.51 & 1.2 & 0.9 & 1.31 & 1.7 \\
\hline 18 & 0.1445 & 0.3371 & 44.6 & 0.53 & 89.55 & 0.5 & 398.7 & 0.29 & 1.03 & 0.83 & 0.79 & 1.32 \\
\hline 19 & 0.1627 & 0.3254 & 41 & 0.2 & 78.43 & 0.04 & 257.9 & 0.13 & 0.24 & 0.33 & 0.17 & 0.37 \\
\hline 20 & 0.131 & 0.4012 & 44.3 & 0.51 & 96.88 & 0.8 & 726.9 & 0.66 & 1.31 & 1.17 & 1.46 & 1.97 \\
\hline 21 & 0.1957 & 0.4049 & 40.6 & 0.16 & 90.48 & 0.53 & 1029 & 1 & 0.69 & 1.16 & 1.53 & 1.69 \\
\hline
\end{tabular}


Table 10: Best results of case 1 without quality loss cost

\begin{tabular}{|c|c|c|c|c|c|c|c|c|c|c|}
\hline Objective & $\begin{array}{l}\text { O. } \\
\text { No. }\end{array}$ & $\begin{array}{l}\text { P. } \\
\text { No. }\end{array}$ & $\begin{array}{l}\text { M. } \\
\text { No. }\end{array}$ & $t_{i j k}$ & $T_{m c, i}$ & Y1 & $Y 2$ & $C_{m f q}$ & $T_{m c}$ & $C_{i d}$ \\
\hline \multirow[t]{8}{*}{$\mathrm{Z1}$} & $\mathrm{O} 1$ & 4 & 2 & 0.077843 & 12.12 & 0.177765 & 0.418894 & 38.95 & 77.43 & 204.27 \\
\hline & $\mathrm{O} 2$ & 1 & 1 & 0.070941 & 6.11 & & & & & \\
\hline & $\mathrm{O} 3$ & 2 & 2 & 0.062235 & 6.98 & & & & & \\
\hline & $\mathrm{O} 4$ & 5 & 4 & 0.035051 & 6.96 & & & & & \\
\hline & O5 & 1 & 1 & 0.038 & 10.02 & & & & & \\
\hline & O6 & 2 & 3 & 0.081529 & 7.45 & & & & & \\
\hline & $\mathrm{O} 7$ & 3 & 4 & 0.048824 & 19.77 & & & & & \\
\hline & O8 & 2 & 3 & 0.066706 & 8.00 & & & & & \\
\hline \multirow[t]{8}{*}{ Z2 } & $\mathrm{O} 1$ & 2 & 3 & 0.083176 & 7.40 & 0.167529 & 0.404816 & 41.78 & 75.62 & 79.98 \\
\hline & $\mathrm{O} 2$ & 1 & 1 & 0.024275 & 14.78 & & & & & \\
\hline & $\mathrm{O} 3$ & 2 & 2 & 0.071176 & 6.64 & & & & & \\
\hline & O4 & 5 & 4 & 0.081443 & 4.36 & & & & & \\
\hline & O5 & 1 & 1 & 0.056392 & 7.27 & & & & & \\
\hline & O6 & 2 & 3 & 0.063176 & 8.17 & & & & & \\
\hline & $\mathrm{O} 7$ & 3 & 4 & 0.064706 & 15.67 & & & & & \\
\hline & O8 & 2 & 3 & 0.031647 & 11.32 & & & & & \\
\hline \multirow[t]{8}{*}{$\mathrm{Z3}$} & $\mathrm{O} 1$ & 4 & 3 & 0.064118 & 11.68 & 0.203176 & 0.377949 & 38.96 & 74.02 & 68.26 \\
\hline & $\mathrm{O} 2$ & 1 & 1 & 0.047333 & 8.36 & & & & & \\
\hline & $\mathrm{O} 3$ & 2 & 2 & 0.079412 & 6.39 & & & & & \\
\hline & O4 & 5 & 4 & 0.048969 & 5.67 & & & & & \\
\hline & O5 & 1 & 1 & 0.048706 & 8.17 & & & & & \\
\hline & O6 & 2 & 3 & 0.045059 & 9.44 & & & & & \\
\hline & $\mathrm{O} 7$ & 3 & 4 & 0.062941 & 16.02 & & & & & \\
\hline & O8 & 2 & 3 & 0.060824 & 8.29 & & & & & \\
\hline \multirow[t]{8}{*}{$\mathrm{Z} 1+\mathrm{Z} 2$} & $\mathrm{O} 1$ & 1 & 1 & 0.060784 & 6.86 & 0.15898 & 0.410106 & 37.32 & 68.21 & 141.49 \\
\hline & $\mathrm{O} 2$ & 1 & 1 & 0.061882 & 6.77 & & & & & \\
\hline & $\mathrm{O} 3$ & 2 & 2 & 0.039412 & 8.56 & & & & & \\
\hline & $\mathrm{O} 4$ & 5 & 4 & 0.041831 & 6.22 & & & & & \\
\hline & O5 & 1 & 1 & 0.055569 & 7.36 & & & & & \\
\hline & O6 & 2 & 3 & 0.070471 & 7.84 & & & & & \\
\hline & O7 & 3 & 4 & 0.062745 & 16.07 & & & & & \\
\hline & O8 & 2 & 3 & 0.056824 & 8.52 & & & & & \\
\hline \multirow[t]{8}{*}{$\mathrm{Z1}+\mathrm{Z3}$} & $\mathrm{O} 1$ & 1 & 1 & 0.064078 & 6.59 & 0.199686 & 0.358204 & 41.04 & 77.00 & 207.39 \\
\hline & $\mathrm{O} 2$ & 1 & 1 & 0.05502 & 7.42 & & & & & \\
\hline & O3 & 2 & 2 & 0.075176 & 6.51 & & & & & \\
\hline & $\mathrm{O} 4$ & 5 & 4 & 0.050753 & 5.55 & & & & & \\
\hline & O5 & 1 & 1 & 0.028667 & 12.76 & & & & & \\
\hline & O6 & 2 & 3 & 0.035176 & 10.69 & & & & & \\
\hline & $\mathrm{O} 7$ & 3 & 4 & 0.048627 & 19.84 & & & & & \\
\hline & $\mathrm{O} 8$ & 2 & 3 & 0.075882 & 7.64 & & & & & \\
\hline $\mathrm{Z} 2+\mathrm{Z} 3$ & $\mathrm{O} 1$ & 2 & 3 & 0.039176 & 10.11 & 0.164706 & 0.378769 & 40.80 & 70.46 & 76.51 \\
\hline
\end{tabular}




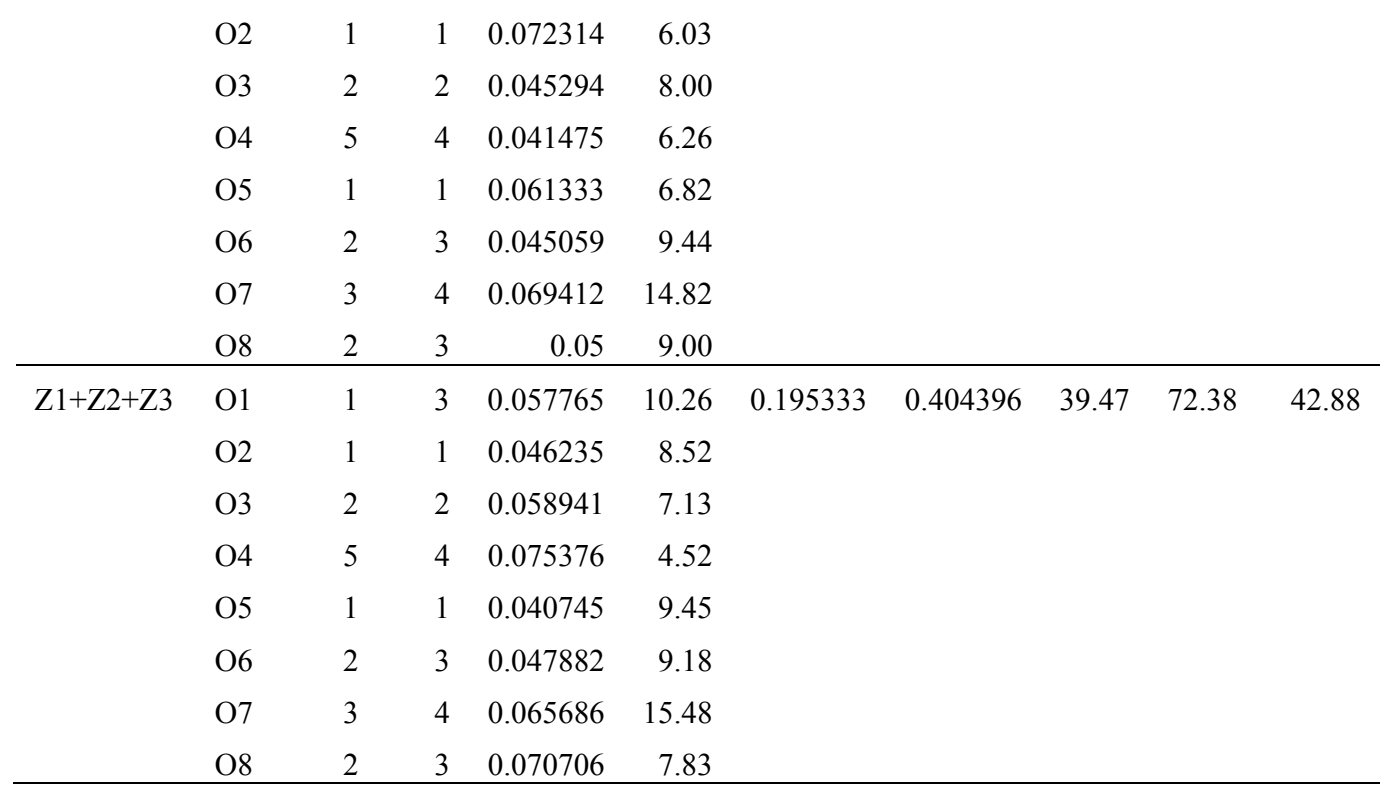


Table 11: Best results of case 2 without quality loss cost

\begin{tabular}{|c|c|c|c|c|c|c|c|c|c|c|}
\hline Objective & $\begin{array}{l}\text { O. } \\
\text { No. }\end{array}$ & $\begin{array}{l}\text { P. } \\
\text { No. }\end{array}$ & $\begin{array}{l}\text { M. } \\
\text { No. }\end{array}$ & $t_{i j k}$ & $T$ & Y1 & $Y 2$ & $C_{m f q}$ & $T_{m c}$ & $C_{i d}$ \\
\hline \multirow[t]{8}{*}{$\mathrm{Z1}$} & $\mathrm{O} 1$ & 2 & 2 & 0.0730588 & 6.577 & 0.2036863 & 0.4137765 & 37.64 & 79.69 & 327.04 \\
\hline & $\mathrm{O} 2$ & 1 & 1 & 0.0536471 & 7.565 & & & & & \\
\hline & $\mathrm{O} 3$ & 2 & 2 & 0.082 & 6.323 & & & & & \\
\hline & $\mathrm{O} 4$ & 5 & 4 & 0.0582471 & 5.147 & & & & & \\
\hline & O5 & 1 & 1 & 0.0319608 & 11.61 & & & & & \\
\hline & O6 & 2 & 3 & 0.0751765 & 7.66 & & & & & \\
\hline & $\mathrm{O} 7$ & 3 & 4 & 0.0333333 & 27.54 & & & & & \\
\hline & O8 & 2 & 3 & 0.0883529 & 7.264 & & & & & \\
\hline \multirow[t]{8}{*}{$\mathrm{Z} 2$} & $\mathrm{O} 1$ & 1 & 3 & 0.0588627 & 10.11 & 0.2035294 & 0.415102 & 36.81 & 69.69 & 154.74 \\
\hline & $\mathrm{O} 2$ & 1 & 1 & 0.0681961 & 6.292 & & & & & \\
\hline & $\mathrm{O} 3$ & 2 & 2 & 0.0829412 & 6.3 & & & & & \\
\hline & $\mathrm{O} 4$ & 5 & 4 & 0.0396902 & 6.431 & & & & & \\
\hline & O5 & 1 & 1 & 0.0758824 & 5.817 & & & & & \\
\hline & O6 & 2 & 3 & 0.0518824 & 8.855 & & & & & \\
\hline & $\mathrm{O} 7$ & 3 & 4 & 0.0552941 & 17.82 & & & & & \\
\hline & $\mathrm{O} 8$ & 2 & 3 & 0.0652941 & 8.063 & & & & & \\
\hline \multirow[t]{8}{*}{$\mathrm{Z3}$} & $\mathrm{O} 1$ & 2 & 3 & 0.0690588 & 7.896 & 0.206549 & 0.4189333 & 37.74 & 71.56 & 85.64 \\
\hline & $\mathrm{O} 2$ & 1 & 1 & 0.0349804 & 10.75 & & & & & \\
\hline & $\mathrm{O} 3$ & 2 & 2 & 0.07 & 6.679 & & & & & \\
\hline & $\mathrm{O} 4$ & 5 & 4 & 0.0636 & 4.916 & & & & & \\
\hline & O5 & 1 & 1 & 0.0358039 & 10.54 & & & & & \\
\hline & O6 & 2 & 3 & 0.0789412 & 7.534 & & & & & \\
\hline & $\mathrm{O} 7$ & 3 & 4 & 0.0660784 & 15.41 & & & & & \\
\hline & $\mathrm{O} 8$ & 2 & 3 & 0.0704706 & 7.838 & & & & & \\
\hline \multirow[t]{8}{*}{$\mathrm{Z} 1+\mathrm{Z} 2$} & $\mathrm{O} 1$ & 4 & 3 & 0.0688235 & 11.18 & 0.204 & 0.4135333 & 35.72 & 68.9 & 207.42 \\
\hline & $\mathrm{O} 2$ & 1 & 1 & 0.0440392 & 8.866 & & & & & \\
\hline & $\mathrm{O} 3$ & 2 & 2 & 0.0824706 & 6.311 & & & & & \\
\hline & $\mathrm{O} 4$ & 5 & 4 & 0.0511098 & 5.531 & & & & & \\
\hline & O5 & 1 & 1 & 0.0583137 & 7.088 & & & & & \\
\hline & O6 & 2 & 3 & 0.0685882 & 7.916 & & & & & \\
\hline & $\mathrm{O} 7$ & 3 & 4 & 0.0617647 & 16.27 & & & & & \\
\hline & $\mathrm{O} 8$ & 2 & 3 & 0.0589412 & 8.393 & & & & & \\
\hline \multirow[t]{8}{*}{$\mathrm{Z1}+\mathrm{Z3}$} & $\mathrm{O} 1$ & 2 & 2 & 0.0436471 & 8.145 & 0.2094118 & 0.4149373 & 37.54 & 69.74 & 158.97 \\
\hline & $\mathrm{O} 2$ & 1 & 1 & 0.039098 & 9.785 & & & & & \\
\hline & $\mathrm{O} 3$ & 2 & 2 & 0.0537647 & 7.412 & & & & & \\
\hline & $\mathrm{O} 4$ & 5 & 4 & 0.0389765 & 6.505 & & & & & \\
\hline & O5 & 1 & 1 & 0.050625 & 7.921 & & & & & \\
\hline & O6 & 2 & 3 & 0.0869412 & 7.3 & & & & & \\
\hline & $\mathrm{O} 7$ & 3 & 4 & 0.0658824 & 15.45 & & & & & \\
\hline & $\mathrm{O} 8$ & 2 & 3 & 0.0897647 & 7.228 & & & & & \\
\hline $\mathrm{Z} 2+\mathrm{Z3}$ & $\mathrm{O} 1$ & 2 & 3 & 0.0754118 & 7.652 & 0.2091765 & 0.4413608 & 35.24 & 70.2 & 193.02 \\
\hline
\end{tabular}




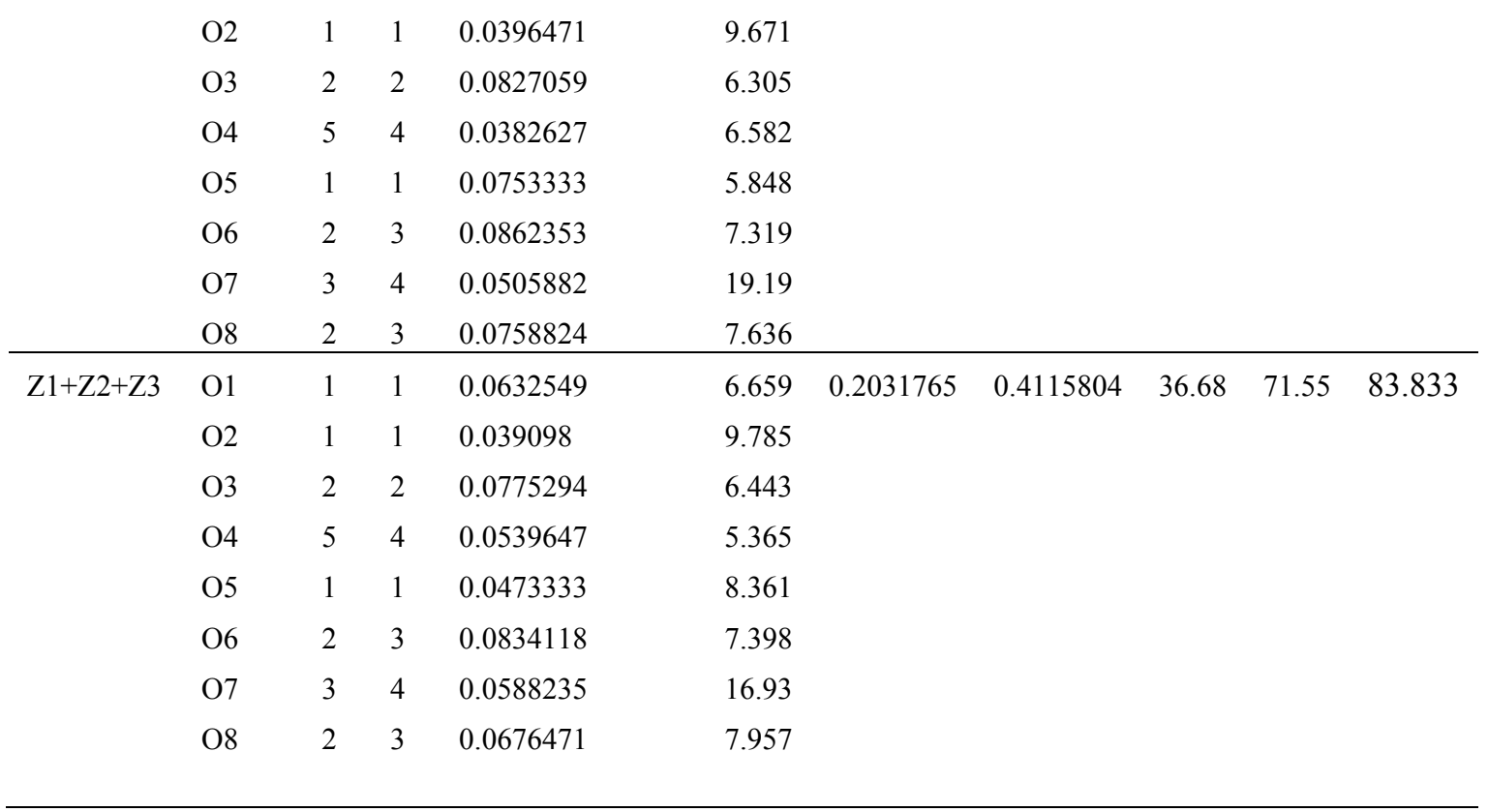


Table 12: Best results of case 1 with quality loss cost

\begin{tabular}{|c|c|c|c|c|c|c|c|c|c|c|c|c|}
\hline Objective & $\begin{array}{l}\text { O. } \\
\text { No. }\end{array}$ & $\begin{array}{l}\text { P. } \\
\text { No. }\end{array}$ & $\begin{array}{l}\text { M. } \\
\text { No. }\end{array}$ & $t_{i j k}$ & $T$ & $Y 1$ & $Y 2$ & $C_{m c}$ & $C_{Q L}$ & $C_{m f g}$ & $T_{m c}$ & $C_{i d}$ \\
\hline \multirow[t]{8}{*}{$\mathrm{Z} 1$} & $\mathrm{O} 1$ & 2 & 2 & 0.05341 & 7.43 & 0.19322 & 0.41379 & 34.81 & 0.68 & 35.49 & 70.19 & 532.38 \\
\hline & $\mathrm{O} 2$ & 5 & 1 & 0.05324 & 7.3 & & & & & & & \\
\hline & $\mathrm{O} 3$ & 2 & 3 & 0.0526 & 8.8 & & & & & & & \\
\hline & $\mathrm{O} 4$ & 3 & 3 & 0.06574 & 13.65 & & & & & & & \\
\hline & O5 & 1 & 1 & 0.0427 & 9.09 & & & & & & & \\
\hline & O6 & 5 & 4 & 0.05807 & 5.16 & & & & & & & \\
\hline & $\mathrm{O} 7$ & 3 & 1 & 0.06586 & 12.87 & & & & & & & \\
\hline & O8 & 1 & 1 & 0.07476 & 5.88 & & & & & & & \\
\hline \multirow[t]{8}{*}{$\mathrm{Z} 2$} & $\mathrm{O} 1$ & 1 & 1 & 0.03758 & 10.12 & 0.16659 & 0.41303 & 40.87 & 4.33 & 45.20 & 66.37 & 446.06 \\
\hline & $\mathrm{O} 2$ & 5 & 4 & 0.03526 & 6.94 & & & & & & & \\
\hline & $\mathrm{O} 3$ & 2 & 2 & 0.03693 & 8.85 & & & & & & & \\
\hline & $\mathrm{O} 4$ & 5 & 2 & 0.07369 & 5.77 & & & & & & & \\
\hline & O5 & 1 & 1 & 0.06204 & 6.76 & & & & & & & \\
\hline & O6 & 5 & 4 & 0.0748 & 4.54 & & & & & & & \\
\hline & O7 & 4 & 2 & 0.05113 & 15.85 & & & & & & & \\
\hline & O8 & 2 & 3 & 0.07853 & 7.55 & & & & & & & \\
\hline \multirow[t]{8}{*}{$\mathrm{Z3}$} & $\mathrm{O} 1$ & 4 & 3 & 0.10047 & 9 & 0.17686 & 0.34145 & 51.69 & 9.49 & 61.17 & 111.24 & 61.27 \\
\hline & $\mathrm{O} 2$ & 1 & 1 & 0.03004 & 12.25 & & & & & & & \\
\hline & $\mathrm{O} 3$ & 2 & 3 & 0.0687 & 7.91 & & & & & & & \\
\hline & $\mathrm{O} 4$ & 3 & 4 & 0.03172 & 28.78 & & & & & & & \\
\hline & O5 & 4 & 2 & 0.05438 & 15.2 & & & & & & & \\
\hline & O6 & 5 & 1 & 0.01667 & 16.2 & & & & & & & \\
\hline & O7 & 3 & 3 & 0.06602 & 13.61 & & & & & & & \\
\hline & O8 & 2 & 2 & 0.04215 & 8.28 & & & & & & & \\
\hline \multirow[t]{8}{*}{$\mathrm{Z} 1+\mathrm{Z} 2$} & $\mathrm{O} 1$ & 2 & 2 & 0.03923 & 8.58 & 0.14102 & 0.40225 & 37.10 & 11.15 & 48.25 & 74.21 & 175.92 \\
\hline & $\mathrm{O} 2$ & 3 & 4 & 0.06967 & 14.77 & & & & & & & \\
\hline & $\mathrm{O} 3$ & 2 & 3 & 0.04154 & 9.81 & & & & & & & \\
\hline & $\mathrm{O} 4$ & 5 & 4 & 0.03926 & 6.48 & & & & & & & \\
\hline & O5 & 1 & 1 & 0.05792 & 7.12 & & & & & & & \\
\hline & O6 & 5 & 4 & 0.0967 & 4.05 & & & & & & & \\
\hline & O7 & 3 & 1 & 0.05245 & 15.51 & & & & & & & \\
\hline & O8 & 2 & 2 & 0.04702 & 7.87 & & & & & & & \\
\hline \multirow[t]{8}{*}{$\mathrm{Z} 1+\mathrm{Z} 3$} & $\mathrm{O} 1$ & 1 & 3 & 0.06787 & 9.08 & 0.18677 & 0.37233 & 40.82 & 3.80 & 44.62 & 108.68 & 96.03 \\
\hline & $\mathrm{O} 2$ & 3 & 3 & 0.0364 & 22.48 & & & & & & & \\
\hline & $\mathrm{O} 3$ & 4 & 2 & 0.08357 & 11.64 & & & & & & & \\
\hline & $\mathrm{O} 4$ & 3 & 1 & 0.06422 & 13.14 & & & & & & & \\
\hline & O5 & 1 & 1 & 0.05595 & 7.32 & & & & & & & \\
\hline & O6 & 2 & 2 & 0.04469 & 8.05 & & & & & & & \\
\hline & $\mathrm{O} 7$ & 3 & 4 & 0.02984 & 30.41 & & & & & & & \\
\hline & O8 & 2 & 2 & 0.07337 & 6.57 & & & & & & & \\
\hline
\end{tabular}




\begin{tabular}{|c|c|c|c|c|c|c|c|c|c|c|c|c|}
\hline \multirow[t]{8}{*}{$\mathrm{Z} 2+\mathrm{Z3}$} & $\mathrm{O} 1$ & 2 & 3 & 0.04851 & 9.12 & \multirow[t]{8}{*}{0.185} & \multirow[t]{8}{*}{0.3817} & \multirow[t]{8}{*}{46.12} & \multirow[t]{8}{*}{3.08} & \multirow[t]{8}{*}{49.20} & \multirow[t]{8}{*}{94.46} & \multirow[t]{8}{*}{92.5} \\
\hline & $\mathrm{O} 2$ & 5 & 1 & 0.07793 & 6.01 & & & & & & & \\
\hline & $\mathrm{O} 3$ & 2 & 3 & 0.07718 & 7.59 & & & & & & & \\
\hline & $\mathrm{O} 4$ & 3 & 4 & 0.03396 & 27.09 & & & & & & & \\
\hline & O5 & 1 & 3 & 0.06913 & 8.95 & & & & & & & \\
\hline & O6 & 5 & 1 & 0.04434 & 8.11 & & & & & & & \\
\hline & O7 & 4 & 2 & 0.03467 & 21 & & & & & & & \\
\hline & $\mathrm{O} 8$ & 2 & 2 & 0.07315 & 6.57 & & & & & & & \\
\hline \multirow[t]{8}{*}{$\mathrm{Z} 1+\mathrm{Z} 2+\mathrm{Z} 3$} & $\mathrm{O} 1$ & 1 & 3 & 0.03956 & 13.93 & \multirow[t]{8}{*}{0.16554} & \multirow[t]{8}{*}{0.36808} & \multirow[t]{8}{*}{42.68} & \multirow[t]{8}{*}{7.54} & \multirow[t]{8}{*}{50.22} & \multirow[t]{8}{*}{78.02} & \multirow[t]{8}{*}{77.18} \\
\hline & $\mathrm{O} 2$ & 5 & 1 & 0.054 & 7.24 & & & & & & & \\
\hline & $\mathrm{O} 3$ & 2 & 3 & 0.05366 & 8.73 & & & & & & & \\
\hline & $\mathrm{O} 4$ & 5 & 2 & 0.06154 & 6.31 & & & & & & & \\
\hline & O5 & 1 & 1 & 0.05049 & 7.94 & & & & & & & \\
\hline & O6 & 5 & 1 & 0.0506 & 7.51 & & & & & & & \\
\hline & O7 & 3 & 4 & 0.05003 & 19.37 & & & & & & & \\
\hline & $\mathrm{O} 8$ & 2 & 2 & 0.06185 & 7 & & & & & & & \\
\hline
\end{tabular}


Table 13: Best results of case 2 with quality loss cost

\begin{tabular}{|c|c|c|c|c|c|c|c|c|c|c|c|c|}
\hline Objective & $\begin{array}{l}\text { O. } \\
\text { No. }\end{array}$ & $\begin{array}{l}\text { P. } \\
\text { No. }\end{array}$ & $\begin{array}{l}\text { M. } \\
\text { No. }\end{array}$ & $t_{i j k}$ & $T$ & $Y 1$ & $Y 2$ & $C_{m c}$ & $C_{Q L}$ & $C_{m f q}$ & $\boldsymbol{T}_{m c}$ & $C_{i d}$ \\
\hline \multirow[t]{8}{*}{$\mathrm{Z} 1$} & $\mathrm{O} 1$ & 1 & 1 & 0.0709 & 6.11 & 0.20418 & 0.41815 & 34.5 & 0.08 & 34.6 & 86.91 & 722.6 \\
\hline & $\mathrm{O} 2$ & 3 & 1 & 0.04099 & 19.14 & & & & & & & \\
\hline & $\mathrm{O} 3$ & 2 & 2 & 0.07884 & 6.41 & & & & & & & \\
\hline & $\mathrm{O} 4$ & 3 & 4 & 0.05624 & 17.57 & & & & & & & \\
\hline & O5 & 1 & 1 & 0.04729 & 8.37 & & & & & & & \\
\hline & O6 & 2 & 2 & 0.07739 & 6.45 & & & & & & & \\
\hline & O7 & 3 & 1 & 0.06846 & 12.48 & & & & & & & \\
\hline & $\mathrm{O} 8$ & 1 & 3 & 0.05688 & 10.39 & & & & & & & \\
\hline \multirow[t]{8}{*}{ Z2 } & $\mathrm{O} 1$ & 2 & 3 & 0.08323 & 7.4 & 0.20537 & 0.41956 & 42.1 & 0.05 & 42.1 & 67 & 554.2 \\
\hline & $\mathrm{O} 2$ & 5 & 2 & 0.0485 & 7.2 & & & & & & & \\
\hline & O3 & 2 & 3 & 0.06187 & 8.23 & & & & & & & \\
\hline & $\mathrm{O} 4$ & 5 & 2 & 0.02977 & 9.81 & & & & & & & \\
\hline & O5 & 1 & 1 & 0.07694 & 5.76 & & & & & & & \\
\hline & O6 & 5 & 1 & 0.03763 & 8.98 & & & & & & & \\
\hline & O7 & 4 & 3 & 0.07085 & 10.98 & & & & & & & \\
\hline & $\mathrm{O} 8$ & 1 & 3 & 0.07265 & 8.63 & & & & & & & \\
\hline \multirow[t]{8}{*}{$\mathrm{Z3}$} & $\mathrm{O} 1$ & 4 & 2 & 0.08442 & 11.57 & 0.20216 & 0.41307 & 40.8 & 0.19 & 41 & 99.8 & 78.57 \\
\hline & $\mathrm{O} 2$ & 5 & 1 & 0.04594 & 7.94 & & & & & & & \\
\hline & $\mathrm{O} 3$ & 2 & 2 & 0.08316 & 6.29 & & & & & & & \\
\hline & $\mathrm{O} 4$ & 3 & 4 & 0.03254 & 28.14 & & & & & & & \\
\hline & O5 & 4 & 3 & 0.04176 & 15.65 & & & & & & & \\
\hline & O6 & 2 & 3 & 0.0894 & 7.24 & & & & & & & \\
\hline & O7 & 3 & 1 & 0.04955 & 16.27 & & & & & & & \\
\hline & $\mathrm{O} 8$ & 2 & 2 & 0.06946 & 6.7 & & & & & & & \\
\hline \multirow[t]{8}{*}{$\mathrm{Z} 1+\mathrm{Z} 2$} & $\mathrm{O} 1$ & 2 & 2 & 0.05547 & 7.31 & 0.20467 & 0.41604 & 36.3 & 0.08 & 36.4 & 72.82 & 794.2 \\
\hline & $\mathrm{O} 2$ & 5 & 2 & 0.07672 & 5.66 & & & & & & & \\
\hline & $\mathrm{O} 3$ & 2 & 2 & 0.08279 & 6.3 & & & & & & & \\
\hline & $\mathrm{O} 4$ & 5 & 2 & 0.03127 & 9.49 & & & & & & & \\
\hline & O5 & 1 & 1 & 0.04795 & 8.27 & & & & & & & \\
\hline & O6 & 2 & 2 & 0.08275 & 6.3 & & & & & & & \\
\hline & O7 & 3 & 1 & 0.03274 & 23.32 & & & & & & & \\
\hline & $\mathrm{O} 8$ & 2 & 2 & 0.08913 & 6.16 & & & & & & & \\
\hline \multirow[t]{8}{*}{$\mathrm{Z1}+\mathrm{Z3}$} & $\mathrm{O} 1$ & 1 & 3 & 0.05864 & 10.14 & 0.20457 & 0.41798 & 39.2 & 0.07 & 39.2 & 98.43 & 111 \\
\hline & $\mathrm{O} 2$ & 3 & 4 & 0.04936 & 19.59 & & & & & & & \\
\hline & $\mathrm{O} 3$ & 2 & 2 & 0.07076 & 6.65 & & & & & & & \\
\hline & $\mathrm{O} 4$ & 3 & 1 & 0.04191 & 18.77 & & & & & & & \\
\hline & O5 & 4 & 2 & 0.11353 & 9.88 & & & & & & & \\
\hline & O6 & 5 & 4 & 0.02072 & 10.12 & & & & & & & \\
\hline & O7 & 3 & 3 & 0.05044 & 16.98 & & & & & & & \\
\hline & $\mathrm{O} 8$ & 2 & 2 & 0.08337 & 6.29 & & & & & & & \\
\hline
\end{tabular}




\begin{tabular}{rrrrrrrrrrrrr}
$\mathrm{Z} 2+\mathrm{Z3}$ & O1 & 1 & 1 & 0.07584 & 5.82 & 0.20092 & 0.41908 & 43.9 & 0.19 & 44.1 & 70.44 & 108.2 \\
& O2 & 1 & 1 & 0.07177 & 6.06 & & & & & & & \\
& O3 & 2 & 2 & 0.0433 & 8.18 & & & & & & & \\
& O4 & 5 & 4 & 0.04846 & 5.7 & & & & & & & \\
& O5 & 1 & 3 & 0.02493 & 20.75 & & & & & & & \\
& O6 & 5 & 4 & 0.04045 & 6.36 & & & & & & & \\
& O7 & 4 & 2 & 0.09627 & 10.76 & & & & & & & \\
& O8 & 1 & 1 & 0.06135 & 6.82 & & & & & & & \\
\hline $\mathrm{Z} 1+\mathrm{Z} 2+\mathrm{Z} 3$ & O1 & 1 & 1 & 0.05804 & 7.11 & 0.20201 & 0.41854 & 35.3 & 0.15 & 35.4 & 77.92 & \\
& O2 & 5 & 4 & 0.06508 & 4.86 & & & & & & & \\
& O3 & 4 & 2 & 0.09817 & 10.65 & & & & & & & \\
& O4 & 3 & 4 & 0.06532 & 15.55 & & & & & & & \\
& O5 & 1 & 1 & 0.06853 & 6.27 & & & & & & & \\
& O6 & 5 & 1 & 0.05774 & 6.98 & & & & & & & \\
O7 & 3 & 3 & 0.04716 & 17.97 & & & & & & & \\
O8 & 2 & 3 & 0.05668 & 8.53 & & & & & & & \\
\hline
\end{tabular}




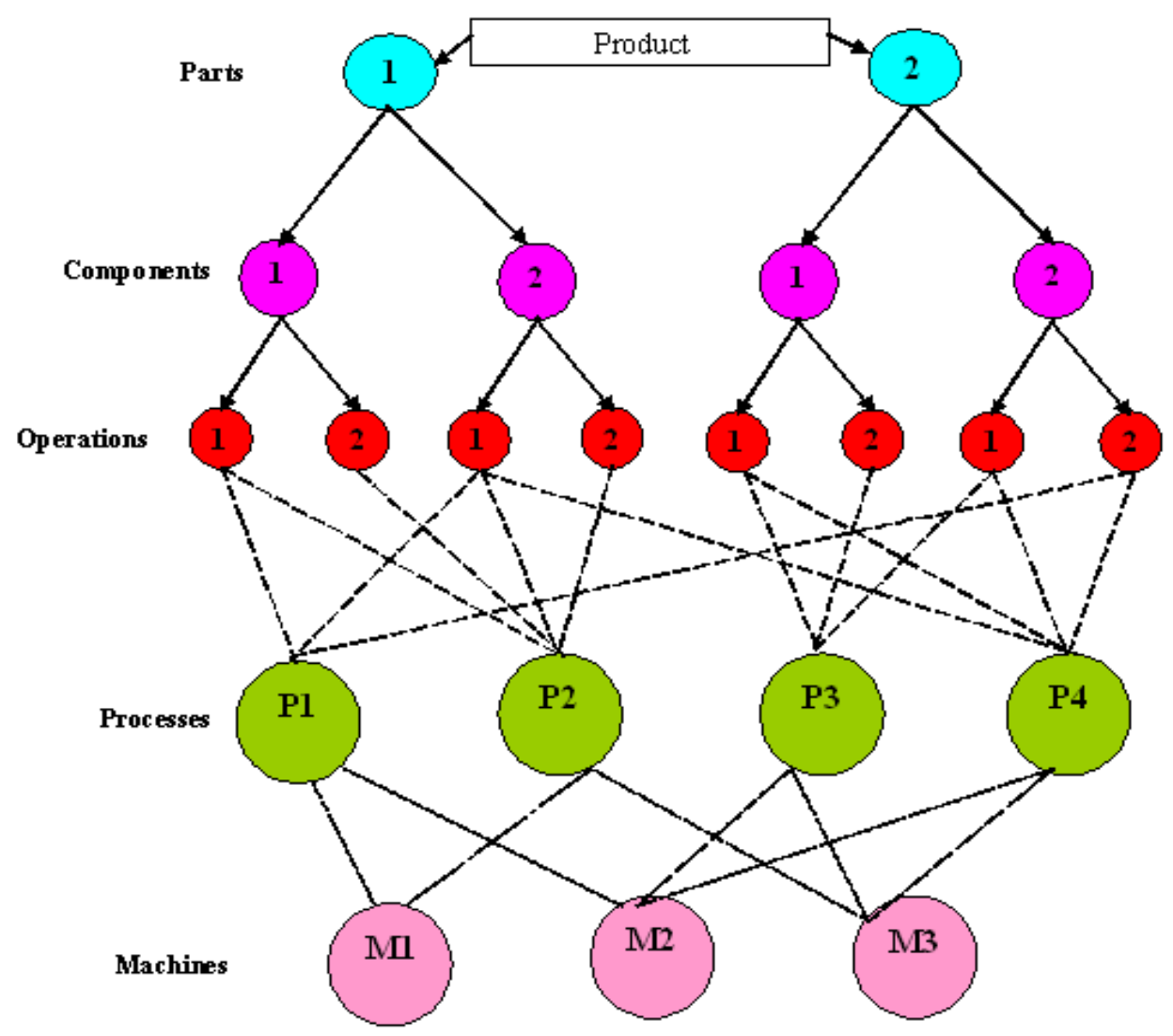

Figure1. General Product Structure 


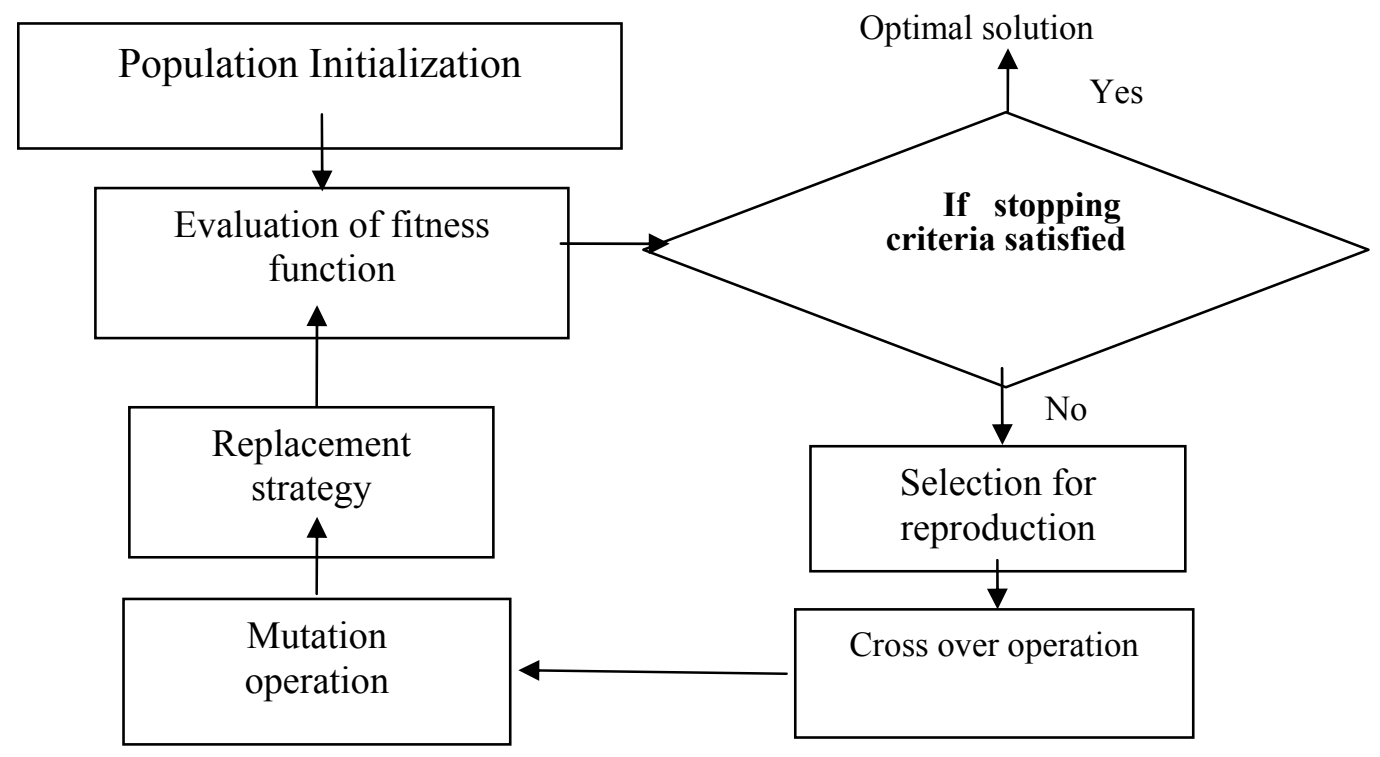

Figure 2. General View of Genetic Algorithm 


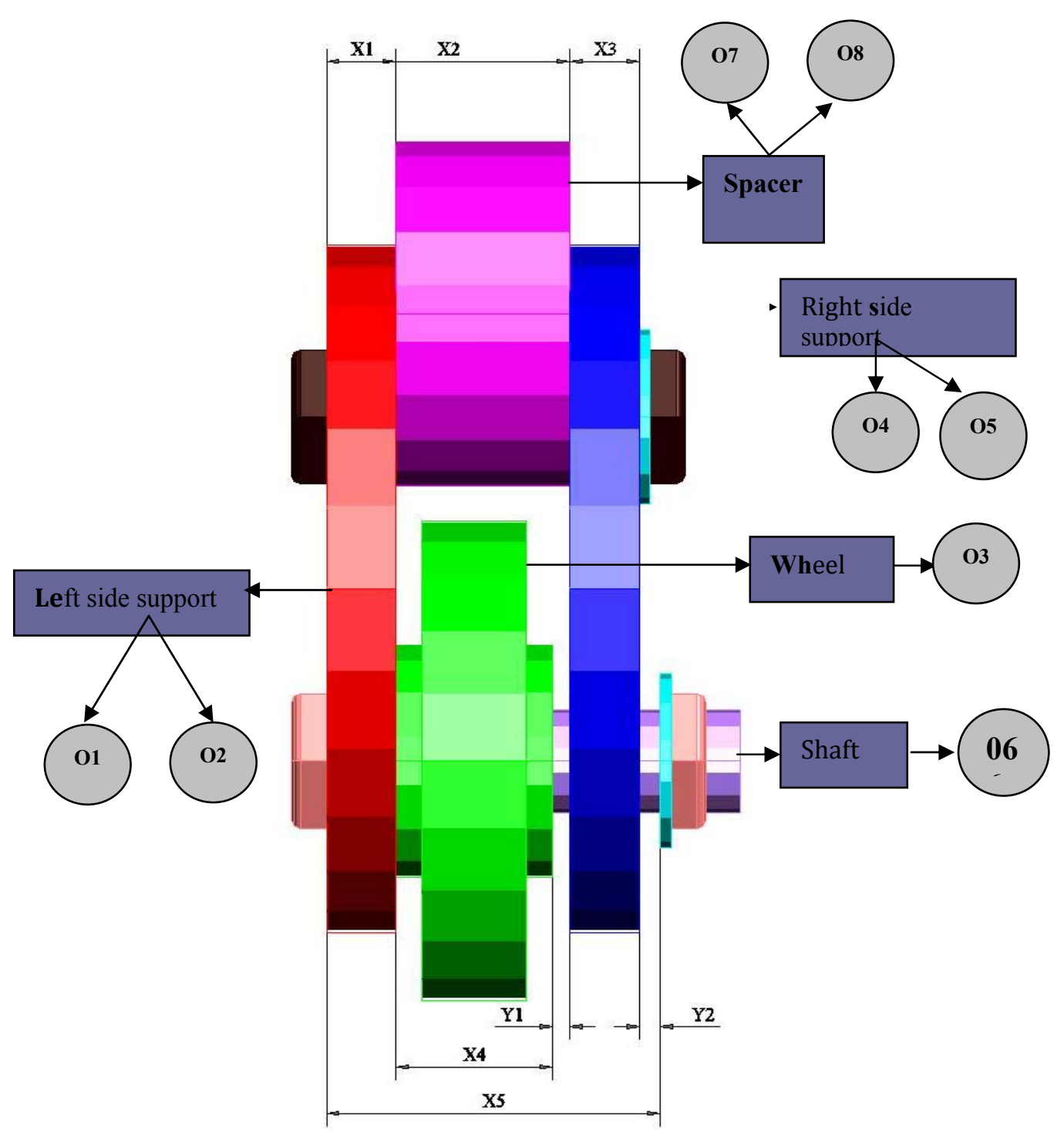

Figure 3.Wheel Mounting Assembly 


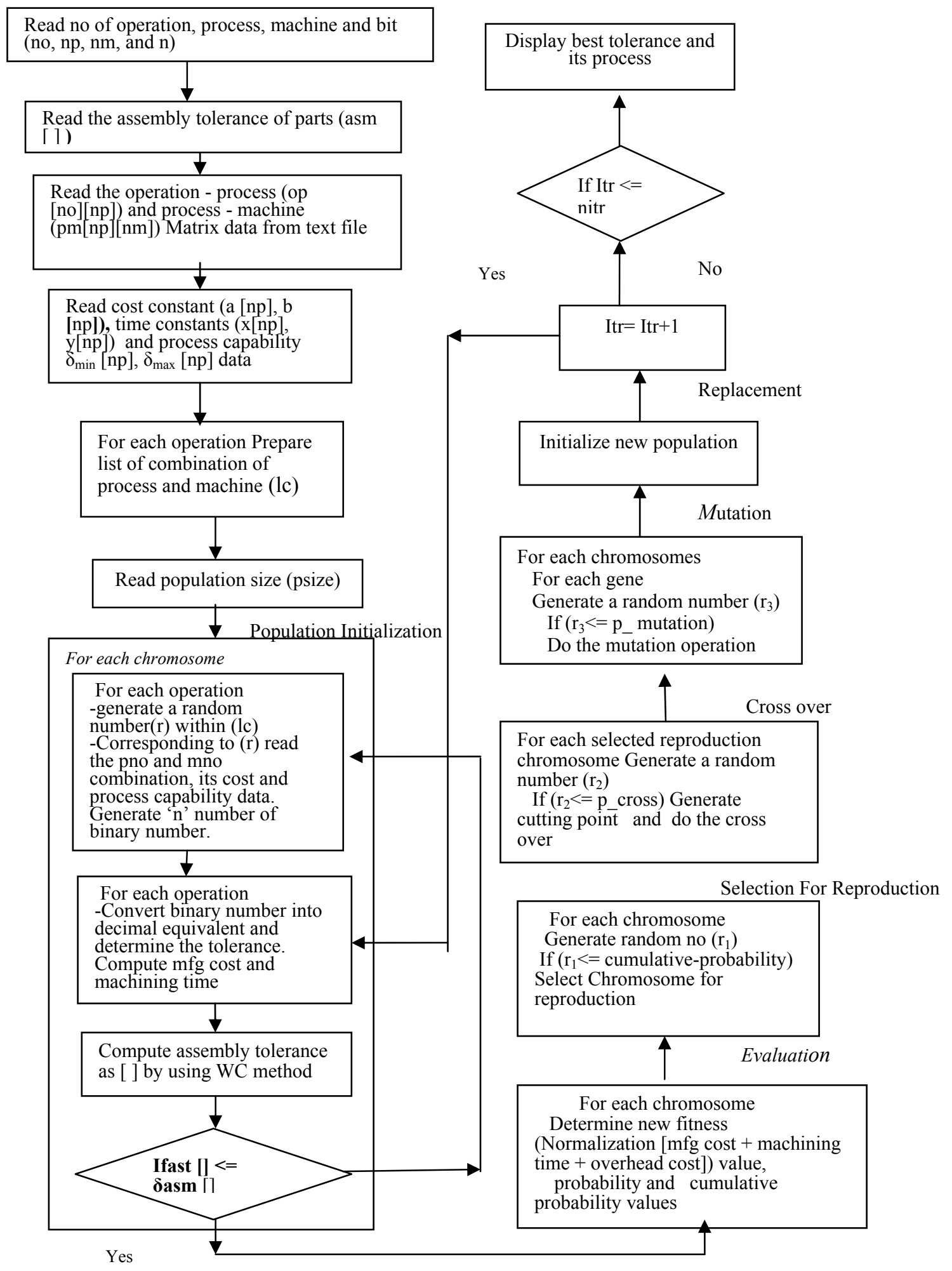

Figure 4.Scheme of the Present Work 


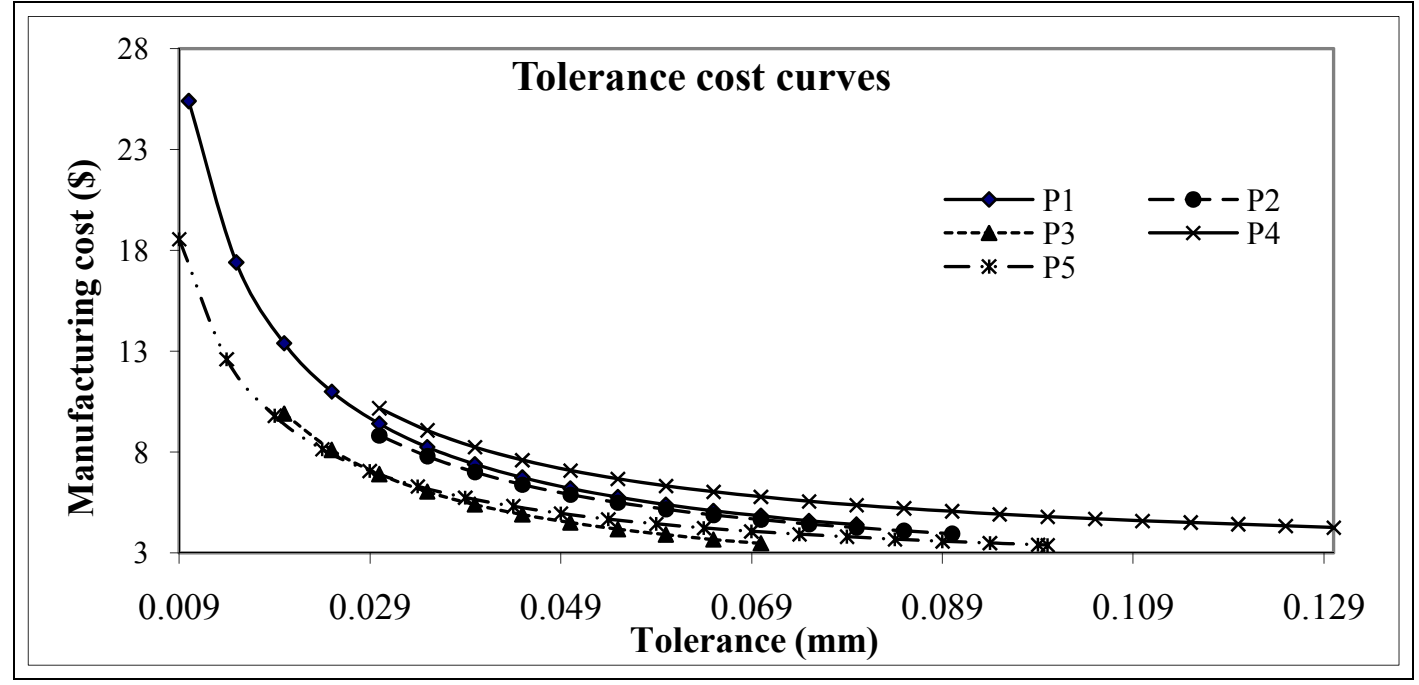

Figure 5 Tolerance Cost Curves

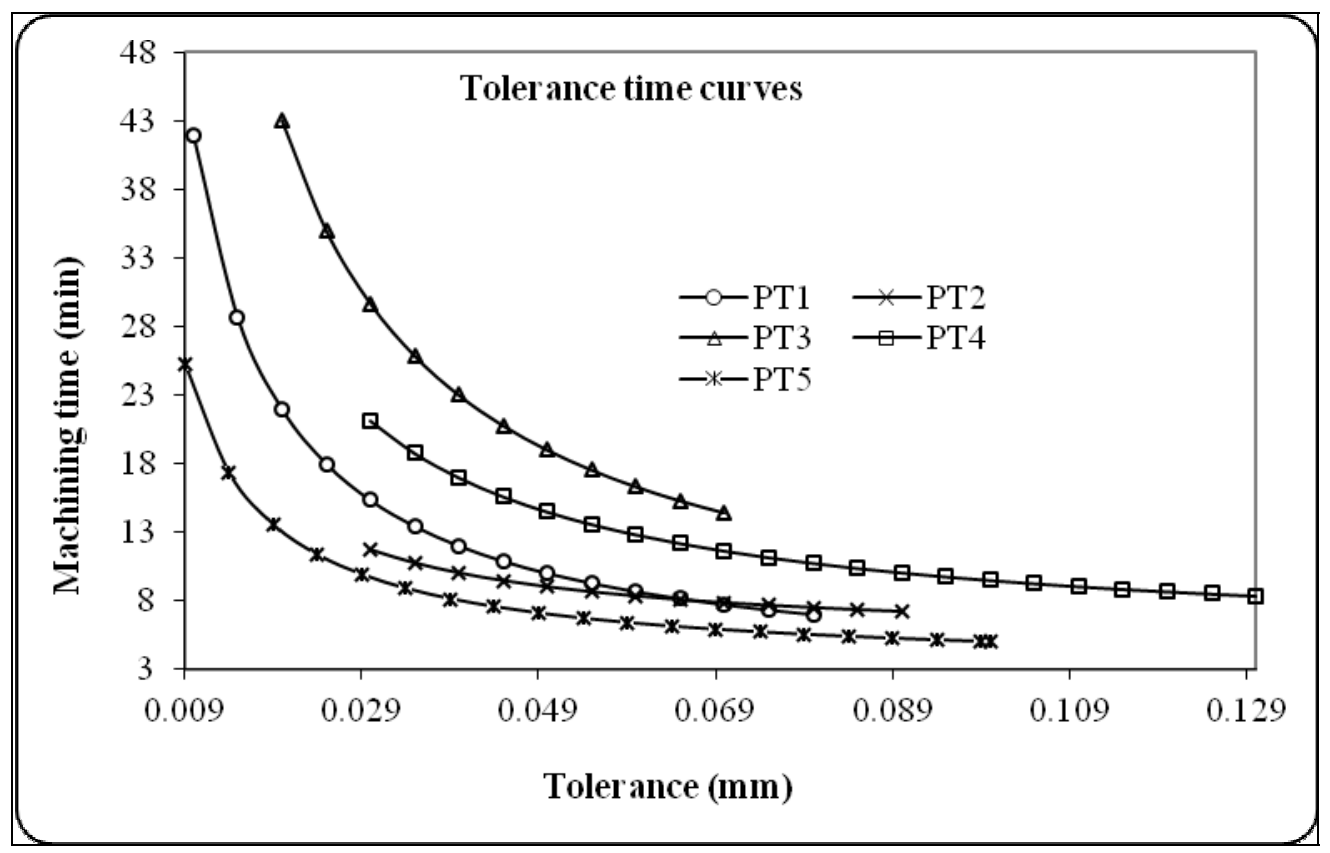

Figure 6. Tolerance Time Curves 


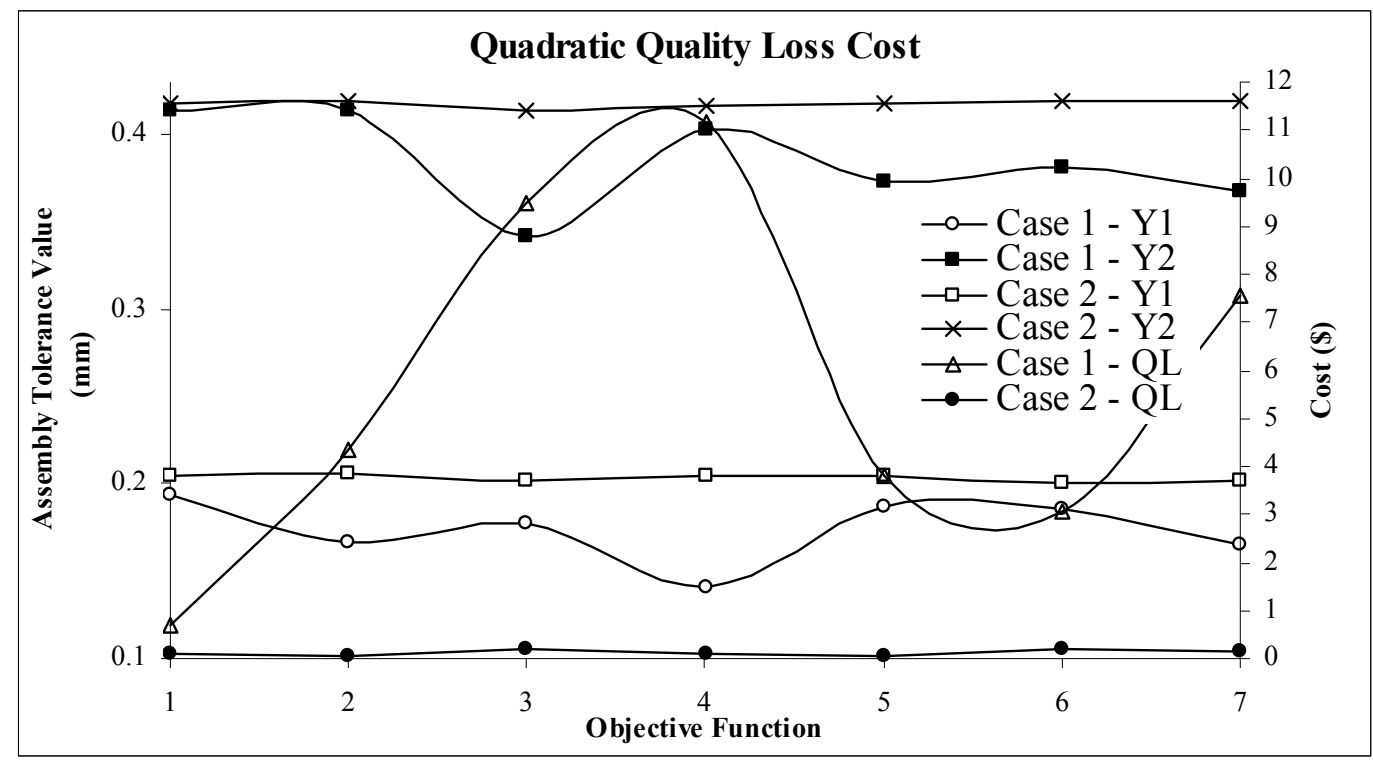

Figure 7: Quadratic Quality Loss Cost for Case 1 and Case 2 for Different Objective Function Combinations

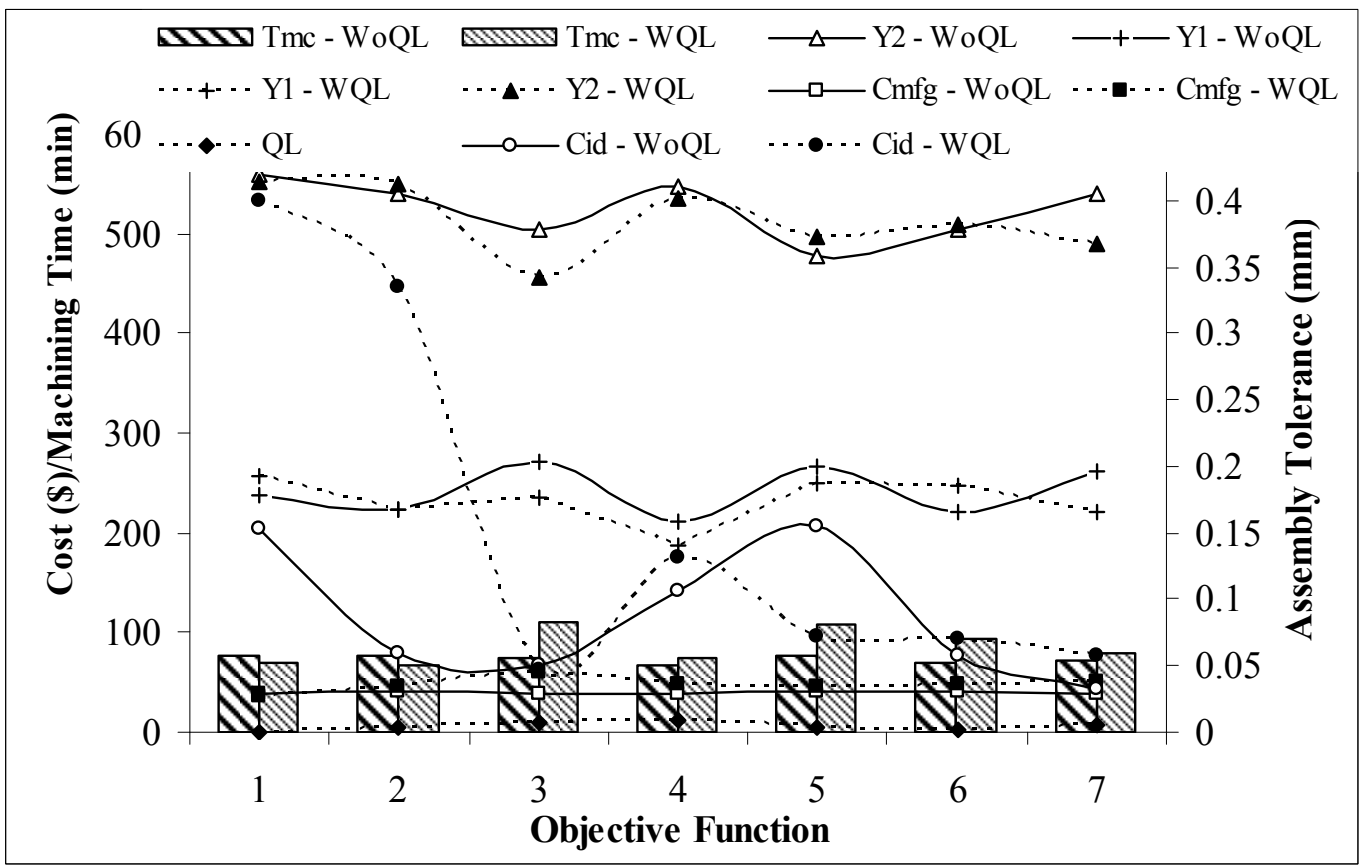

Figure 8: Comparison of Case 1 with and without Quality Loss Cost 


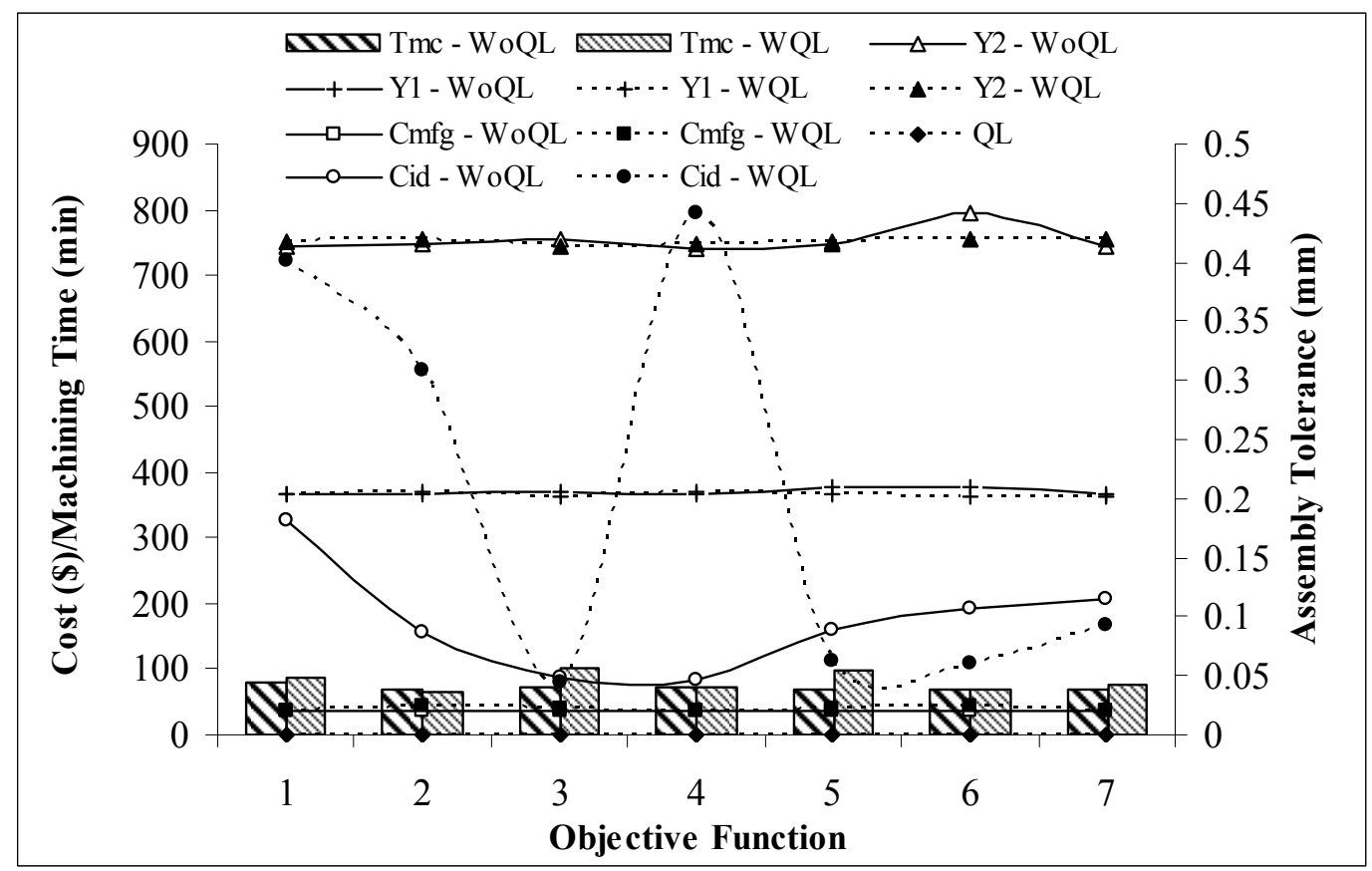

Figure 9: Comparison of Case 2 with and without Quality Loss Cost 